Aus der Abteilung Arbeits- und Sozialmedizin

(Prof. Dr. med. E. Hallier)

im Zentrum Arbeits-, Sozial-, Umweltmedizin und Dermatologie der Medizinischen Fakultät der Universität Göttingen

\title{
Polymorphismen der Glutathion-S-Transferase A1 in Zusammenhang mit malignen hämatologischen Erkrankungen
}

\author{
INAUGURAL-DISSERTATION \\ zur Erlangung des Doktorgrades \\ der Medizinischen Fakultät \\ der Georg-August-Universität zu Göttingen
}

vorgelegt von

Anja Siede

aus Blankenburg

Göttingen 2009 
Dekan:

1. Berichterstatter:

2. Berichterstatter/in:

3. Berichterstatter/in:

Tag der mündlichen Prüfung:
Prof. Dr. med. C. Frömmel i.V. Prof. Dr. med. Hallier Prof. Dr. med. Haase Prof. Dr. rer. nat. Virsik-Köpp 16.09.2010 


\section{Inhaltsverzeichnis}

1 Einleitung 1

1.1 Einführung 1

1.2 Glutathion-S-Transferasen 3

1.2.1 Einteilung der GSTs 3

1.2.2 $\alpha$-Glutathion-S-Transferasen $\quad 5$

1.2.3 Polymorphismen der GSTs $\quad 6$

$\begin{array}{ll}\text { 1.3 Maligne hämatologische Erkrankungen } & 7\end{array}$

$\begin{array}{ll}\text { 1.3.1 Akute myeloische Leukämie (AML) } & 7\end{array}$

1.3.2 Einteilung der AML $\quad 8$

1.3.3 Myelodysplastisches Syndrom (MDS) 8

1.3.4 Sekundäre Leukämien und MDS-Syndrom 10

1.4 Beschreibung von Versuchsanordnung und

$\begin{array}{ll}\text { Fragestellung der Arbeit } & 12\end{array}$

2 Material und Methoden $\quad 13$

$\begin{array}{ll}2.1 \text { Material } & 13\end{array}$

2.1.1 Geräte 13

2.1.2 Reagenzien 14

2.1.3 Chemikalien 14

$\begin{array}{ll}2.2 \text { Methoden } & 15\end{array}$

2.2.1 DNS-Isolierung aus Vollblut $\quad 15$

2.2.2 DNS-Konzentrations- und Reinheitsbestimmung 16

2.2.3 Polymerase-Ketten-Reaktion (PCR) 17

2.2.4 Agarose-Gelelektrophorese 19

2.2.5 Restriktionsenzymverdau 19

2.2.6 Karyotypanalyse 21

2.3 Statistische Auswertung $\quad 22$ 
3 Ergebnisse $\quad 23$

3.1 Einführung 23

3.2 Genotypgesamtübersicht 23

$\begin{array}{ll}3.3 \text { AML-Zytogenetik } & 24\end{array}$

3.4 MDS-Zytogenetik 25

3.5 FAB-Klassifikation der AML-Subgruppe 26

3.6 FAB-Klassifikation der MDS-Subgruppe 27

3.7 Sekundäre / Therapie-induzierte AML und MDS 28

4 Diskussion $\quad 30$

$\begin{array}{ll}4.1 \text { Einführung } & 30\end{array}$

4.2 GSTA1-Polymorphismus $\quad 30$

4.3 GSTs und Medikamentenresistenz $\quad 32$

4.4 GSTA1 und VOD (Veno-occlusive disease) 34

4.5 Kolorektale Malignome, Mammakarzinome und $\begin{array}{ll}\text { GSTs } & 34\end{array}$

4.6 Sekundäre und Therapie-induzierte Malignome 36

4.7 Nicht maligne Erkrankungen und GSTA1 38

5 Zusammenfassung $\quad 39$

6 Abkürzungsverzeichnis $\quad \mathbf{4 0}$

7 Literaturverzeichnis $\quad 43$ 


\section{Einleitung}

\subsection{Einführung}

Der menschliche Organismus ist täglich den verschiedensten Umwelt-, Fremd- und Arbeitsstoffen ausgesetzt. Er nimmt diese über die Nahrung oder die Atemluft auf, um sie anschließend wie endogene Abbauprodukte auszuscheiden.

Viele dieser exogenen Fremdstoffe sind lipophil und benötigen metabolische Modifizierungen wie auch manche endogen synthetisierte Stoffe (Hormone), um eliminiert werden zu können. Diese Modifizierungen können die Fremdstoffmetabolisierenden Enzyme (FME) vornehmen. Die FME werden in Phase-I-Enzyme und Phase-II-Enzyme eingeteilt. Erstgenannte (z.B. Cytochrom-P450) vermitteln vorwiegend oxidative Reaktionen, wobei aus apolaren, lipophilen Stoffen polare und reaktive Metabolite entstehen können. Die konjugierten Metaboliten sind in der Regel leichter renal und biliär eliminierbar. Im Allgemeinen ist damit die Entstehung biologisch inaktiver Metaboliten verbunden. Allerdings ist es auch möglich, dass mit der Metabolisierung eine Aktivierung von Verbindungen oder auch die Bildung von DNS-Addukten verbunden sein kann (Schulz und Hallier, 1999).

Nebert (1997) schätzte die Anzahl aller Arzneistoffe und umweltrelevanten Schadstoffe, die erst nach Aktivierung durch FME ihre unerwünschte Wirkung entfalten, auf 25\%. Dabei existieren große Aktivitätsunterschiede der FME, die bei gleicher Exposition an Umwelt- und Arbeitsstoffen individuelle Unterschiede in der Toxizität und in der Krebsentstehung zur Folge haben (Schulz und Hallier, 1999). Diese Unterschiede können erhebliche Ausmaße (das 10-200fache) annehmen (Hallier, 2002).

In der Vergangenheit wurde eine Reihe von Polymorphismen der FME beschrieben, die mit einer erhöhten Suszeptibilität im Bezug auf die Entstehung verschiedener Malignome assoziiert werden konnten (Seidegard et al., 1990; Daly et al., 1993; Zhong et al., 1993; Chen et al., 1996; Harries et al., 1997). Da die Enzyme der GSTFamilie eine zentrale Rolle in der Entgiftung spielen, waren und sind auch ihre Polymorphismen Gegenstand der Forschung. 


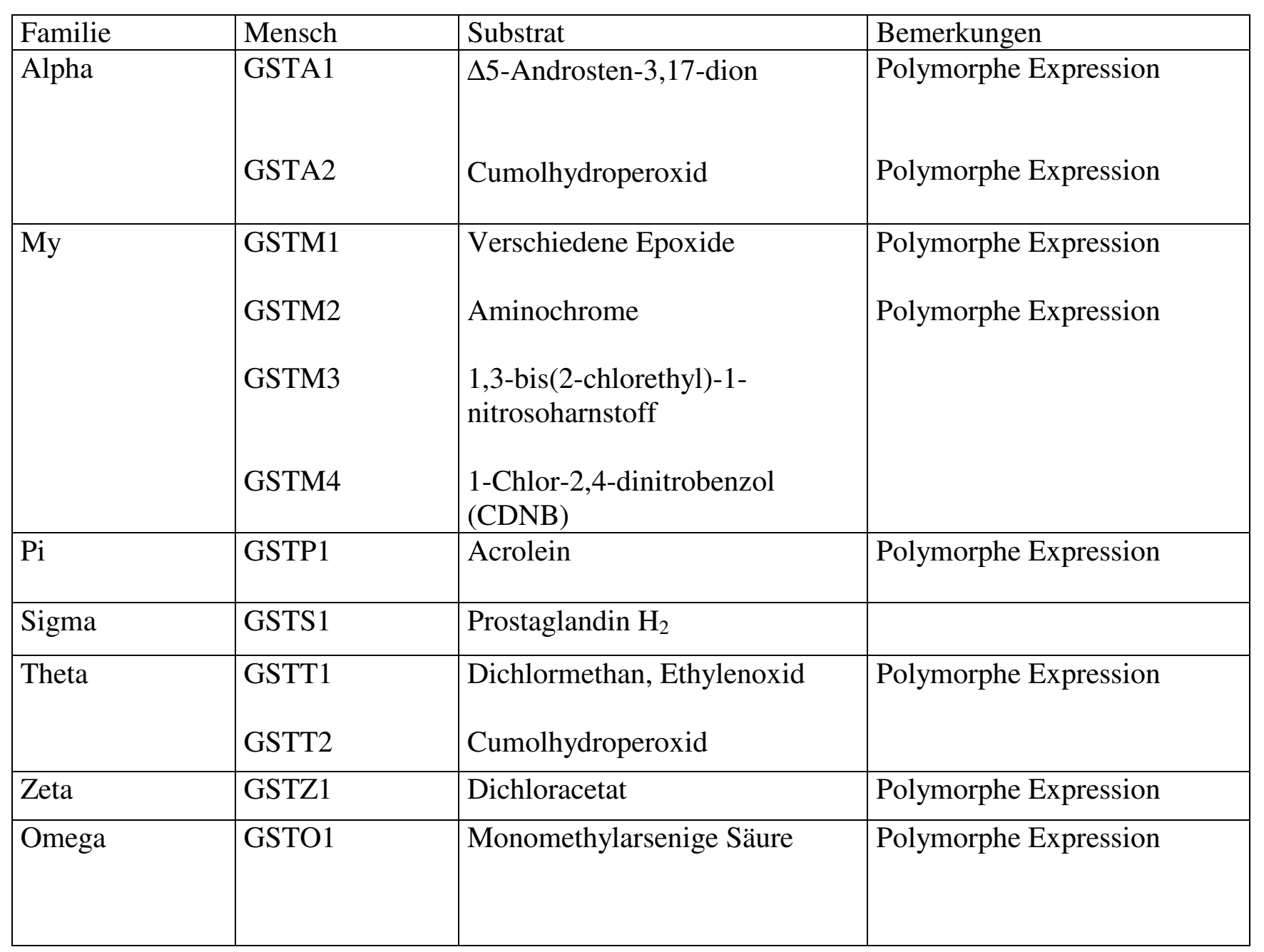

Tabelle 1: Übersicht wichtiger zytosolischer Glutathion- $S$-Transferasen (aus Hayes et al., 2005, S. 62) 


\subsection{Glutathion-S-Transferasen}

Die in Tabelle 1 aufgeführten Glutathion-S-Transferasen (GSTs) sind wichtige Enzyme des Phase-II-Stoffwechsels. Dieser Enzymkomplex verwendet L-Glutathion zur Konjugation vieler verschiedener exogener und endogener Verbindungen. Als Substrate werden nicht nur die Metaboliten des Phase-I-Stoffwechsels genutzt, sondern auch chemische Karzinogene, Medikamente und Produkte des oxidativen Stresses, wenn sie ein für die Reaktion mit Glutathion geeignetes elektrophiles Zentrum besitzen (Hayes und Pulford, 1995). Des Weiteren können GSTs auch als Peroxidase oder Isomerase fungieren (Hayes und Pulford, 1995).

Die Glutathionkonjugation findet hauptsächlich in der Leber statt, wobei die Konjugate im Wesentlichen über die Gallenflüssigkeit und von dort mit den Faeces ausgeschieden werden. Der restliche Teil gelangt durch die Blutbahn zur Niere, wird dort durch die $\gamma$-Glutamyltranspeptidase und die Aminopeptidase $\mathrm{M}$ zu einem Cystein-Konjugat abgebaut. Dieses kann zur Mercaptursäure acetyliert oder durch die $\beta$-Lyase zu einem Sulfhydrylderivat des Ausgangsstoffes metabolisiert werden (Commandeur et al., 1995). Auch wenn einige dieser Konjugationsreaktionen Substrate zu toxischen Metaboliten umwandeln können (Dekant et al., 1990; Garnier et al., 1996), ist doch Glutathion für zahlreiche Fremdstoffe und Arzneimittel eines der wichtigsten zellulären Schutzmoleküle gegenüber elektrophilen, reaktiven Verbindungen. So wird eine Reihe von Alkylanzien, wie Cyclophosphamid, Melphalan, Chlorambucil oder Thiotepa effektiv detoxifiziert (Dirven et al., 1994; Dirven et al., 1996; Paumi et al., 2001).

\subsubsection{Einteilung der GSTs}

GSTs sind weit verbreitet in der Natur und wurden sowohl bei Pro- als auch bei Eukaryoten identifiziert (Hayes und Pulford, 1995). Untersuchungen bei Säugetieren haben gezeigt, dass es 7 verschiedene GST-Klassen gibt, welche ihrer genetischen Sequenz entsprechend in alpha, my, pi, sigma, theta, zeta und omega eingeteilt werden (Board et al., 2000; Tetlow et al., 2001; Hayes et al., 2005). Die meisten GSTs befinden sich im Zytoplasma, wobei auch eine mitochondriale GST (Pemple et al., 1996) und einige mikrosomale GST-Formen beschrieben wurden (van Ommen et al.,1990; Hayes und Pulford, 1995). 
Die löslichen GSTs sind aus Dimeren bestehende Enzyme (van Ommen et al., 1990). Bei der Ratte wurden bereits 11 Untereinheiten charakterisiert. Es wird vermutet, dass noch weitere existieren (Coles und Ketterer, 1990). Diese Untereinheiten können in ihrer jeweiligen Klasse aus Homo- oder auch aus Heterodimeren zusammengesetzt sein. Die Identität von Mitgliedern einer GST-Klasse ist größer als 40\%, wohingegen die Identität verschiedener Klassen geringer als 30\% ist (Hayes und Pulford, 1995). Eine Übersicht der zytoplasmatischen GST-Isoenzyme der Ratte zusammen mit ihren bevorzugten Substraten zeigt Tabelle 2.

Tabelle 2: Isoenzyme der GST-Familien der Ratte und deren bevorzugte Substrate. Angegeben sind die Homodimere; die Familienpräferenzen stimmen im Wesentlichen zwischen den Säugetierspezies überein.

GST-Familie

Präferentielles Substrat

\section{Alpha}

GST 1-1

$\Delta 5$-Androsten -3,17-dion,

GST 2-2

$\mathrm{N}$-Acetyl-p-benzochinonimin

GST 8-8

Cumolhydroperoxid

GST 10-10

4-Hydroxynonenal

My

Cumolhydroperoxid

GST 3-3

Bromsulphthalein, 1,2-Dichlor-4-nitrobenzol,

GST 4-4

Benzo[a]pyren-4,5-oxid

trans-Stilbenoxid, trans-4-Phenyl-3-buten-2-on

GST 6-6

Leukotrien A4,

1,2-Dichlor-4-nitrobenzol

GST 9-9

GST 11-11

Pi

GST 7-7

(+)-anti-Benzo[a]pyren-7,8-

diol-9,10-oxid

Theta

GST 5-5

1,2-Epoxy-3-

(p-nitrophenoxy)propan,

Cumolhydroperoxid,

Dichlormethan

Benzo $[a]$ pyren-4,5-oxid

(nach Hayes und Pulford, 1995, S. 474) 
Die GST-Familie ist wie andere Enzymkomplexe auch durch eine überlappende Substratspezifität gekennzeichnet (Board et al., 2000). So wird 1-Chlor-2,4dinitrobenzol (CDNB) von den GST-Klassen alpha, my und pi sehr gut, von dem Omega-Isoenzym weniger gut (Board et al., 2000) umgesetzt und gilt daher als universelles GST-Substrat. Allerdings zeigte die GSTT1 keine Aktivität gegenüber CDNB (Meyer et al., 1991). Die Theta-Klasse, welche unter anderem in menschlichen Erythrozyten isoliert werden konnte (Schröder et al., 1992), weist gegenüber dem Substrat Methylbromid die höchste Enzymaffinität auf (Hallier et al., 1990).

Die Enzymaktivität ist von verschiedenen Faktoren abhängig, so dass die Expression je nach Spezies, Alter, Geschlecht oder auch Gewebe variieren kann. Andererseits können zusätzlich auch Fremdstoffe, die als Enzyminduktoren fungieren, die Expressionsrate beeinflussen. Weiterhin wurde beim Menschen eine Reihe von Polymorphismen der GSTs beschrieben (siehe 1.2.3).

\subsection{2 $\alpha$-Glutathion-S-Transferasen}

Die GSTs der alpha-Klasse werden vorrangig in der Leber exprimiert (van Ommen et al., 1990; Morel et al., 1993). Aber auch andere Gewebe wie beispielsweise Niere (Lörper et al., 1996) und Magen (Howie et al., 1990) können, wenn auch in geringerem Maße, alpha-Glutathion-S-Transferasen exprimieren. Es existieren mehrere Gene und Pseudogene dieser Enzymfamilie, welche in einem engen Cluster auf dem Chromosom 6 lokalisiert sind (Morel et al., 1994). Bislang konnte nicht nur die organspezifische Variabilität in der Enzymexpression nachgewiesen werden, sondern es sind auch tumorspezifische Unterschiede in der Expressionsrate der $\alpha$ GSTs beschrieben worden (Morel et al., 1994). So konnte eine geringere Expression beispielsweise für das Nierenzellkarzinom (Klöne et al., 1990; Eickelmann et al., 1994) und bei Magen- sowie Lebertumoren (Howie et al., 1990) festgestellt werden. Im Gegensatz dazu wiesen Lungentumoren eine erhöhte Expression an GST alpha auf (Carmichael et al., 1988), wohingegen für Brust- und Darmkrebs gleichbleibende Enzymlevel ermittelt wurden (Howie et al., 1990).

Die $\alpha$-GSTs greifen auch in der Detoxifikation von Alkylanzien ein. So wird Busulfan, eine alkylierende Substanz, welche primär zur Therapie hämatologischer 
Malignome herangezogen wird, hauptsächlich durch das Isoenzym GSTA1-1 eliminiert (Czerwinski et al., 1996). Diese hohe Enzym-Substrat-Affinität konnte auch mithilfe von ECV 304-Zellen, in einem Endothel-Zell-Modell bestätigt werden (Ritter et al., 2002). Gezeigt wurde dabei, dass eine Überproduktion an GSTA1-1 im Zellmodell eine Busulfankonjugation nach sich zieht, was letztendlich den toxischen Effekt der antineoplastischen Verbindung auf den Zellzyklus reduziert (Ritter et al., 2002). Anhand einer anderen Untersuchung konnte ein zytoprotektiver Effekt der GSTA1 wie auch der GSTT1 in Erythrozyten veranschaulicht werden (Wang et al., 2000). Wang et al. zeigten zunächst eine vermehrte Expression an GSTA1, sowie GSTT1 in Erythrozyten im Vergleich zur weißen hämatologischen Zellreihe. Mithilfe von CDNB als Substrat konnte eine hohe Konjugationsaktivität der zuvor genannten Enzyme nachgewiesen werden. Daraus ließ sich postulieren, dass bei hoher Aktivität von GSTA1 und GSTT1 vermehrt Fremdstoffe, die wie CDNB Substrate dieser Enzyme darstellen, eliminiert werden können.

In-vitro-Untersuchungen der GSTA1 und GSTA2 in Bezug auf die Induzierbarkeit der Enzyme in der menschlichen Leber zeigten, dass 2-Dithiolethion und Phenobarbital Induktoren sind, wobei die erstgenannte Verbindung über das größere Induktionspotential verfügt (Morel et al., 1993).

\subsubsection{Polymorphismen der GSTs}

Polymorphismen oder Sequenzvariationen sind in vielen Genen zu finden. Bei den GSTs gibt es z.B. bei der GSTM1 und der GSTT1 Deletionspolymorphismen, die zum völligen Verlust der enzymatischen Aktivität führen (Seidegard et al., 1988; Pemple et al., 1994). Daneben gibt es auch noch Einzelnukleotidpolymorphismen, die z.B. in der GSTP1 einen Aminosäureaustausch zur Folge haben (Henderson et al., 1998).

Für die GSTA1 und GSTA2 ergab die Durchsuchung der EST-Datenbank, welche eine Sammlung aus über 1,8 Millionen Teil-c-DNS-Sequenzen ist, zehn mutmaßliche Polymorphismen in codierenden Regionen der GSTA1- und GSTA2-Gene, von denen sechs sequenziert werden konnten (Tetlow et al., 2001).

Die proximale Promotorregion der menschlichen GSTA1- und der GSTA2-Gene als mögliche Lokalisation von Polymorphismen wurde intensiv untersucht. So fanden 
Lörper et al. (1998) in dieser Region charakteristische Bindungsstellen für aktivierende Transkriptionsfaktoren. Die Forschungsgruppe um Coles untersuchte 2001 die Promotorregion im Hinblick auf die GSTA1- und GSTA2-Expressionsrate in der menschlichen Leber. Die Analyse der Promotorregion für die GSTA1 ergab zwei Allele: $h G S T A l * A=(-567 \mathrm{~T},-69 \mathrm{C},-52 \mathrm{G})$ und $h G S T A 1 * B=(-631 \mathrm{G},-567 \mathrm{G}$, -69T, -52A). Daraus ergeben sich drei Allelkombinationen für die GSTA1: homozygot $h G S T A l * A$, heterozygot $h G S T A l * A / B$ und homozygot $h G S T A l * B$. Coles et al. (2001b) konnten zeigen, dass $h G S T A l * B$ eine weitaus geringere Expressionsrate im Zytoplasma im Vergleich $\mathrm{zu}$ den beiden anderen Allelen aufweist.

In einer retrospektiven Studie wurde der $h G S T A l * B$-Genotyp mit einem erhöhten Risiko für ein kolorektales Karzinom assoziiert (Sweeney et al., 2002). Dieser Polymorphismus ist möglicherweise einerseits signifikant für Veränderungen im Metabolismus von Xenobiotika und spielt andererseits eine Rolle in der Krebsentstehung (Coles et al., 2001b; Board, 2002).

\subsection{Maligne hämatologische Erkrankungen}

\subsubsection{Akute myeloische Leukämie (AML)}

Die akute myeloische Leukämie ist eine maligne klonale Neoplasie, bei der eine diffuse autonome Proliferation der myeloischen Leukozytenreihe besteht, die mit einer Ausschwemmung unreifer Blasten ins Blut einhergeht. Die dadurch resultierende Knochenmarkinsuffizienz ist für die klinische Symptomatik verantwortlich (Anämie, Thrombozytopenie). Mit einem Vorkommen von 3,7 Patienten pro 100000 Einwohner (Deschler und Lübbert, 2006) ist diese Erkrankung mit $80 \%$ die häufigste Leukämie im Erwachsenenalter. Ätiologisch werden verschiedene Faktoren diskutiert. Es werden Viren, prädisponierende genetische Faktoren wie Trisomie-21 (Forestier et al., 2008) und Knochenmarkschädigungen durch chemische Substanzen (Benzol, Zytostatika) oder ionisierende Strahlung mit der Krankheitsentstehung in Verbindung gebracht. Zusätzlich können ein vorbestehendes MDS-Syndrom oder eine bestehende Polycythaemia vera ätiologisch in Betracht gezogen werden. Häufig tritt die akute myeloische Leukämie auch nach 
Chemotherapie als sogenannte sekundäre bzw. Therapie-assoziierte Leukämie auf (Karp und Smith, 1997).

\subsubsection{Einteilung der AML}

Die Einteilung der AML-Subtypen erfolgt durch die FAB-Klassifikation (FrenchAmerican-British-Group) anhand morphologischer Kriterien. Die Unterschiede in der Chromatinstruktur, der Kernform, der Vakuolisierung und in der Zellgröße werden mithilfe von Messungen verschiedener Oberflächen- und zytoplasmatischer Marker bestimmt.

Die AML-Subtypen werden wie folgt charakterisiert:

M0 undifferenzierte akute Leukämie

M1 AML ohne Ausreifung

M2 AML mit Ausreifung

M3 Promyelozytenleukämie

M4 akute myelomonozytäre Leukämie

a) ohne Eosinophilie

b) mit Eosinophilie

M5 akute monozytäre Leukämie

a) undifferenziert

b) differenziert

M6 akute Erythroleukämie

M7 akute megakaryozytäre Leukämie.

Zytogenetisch sind für einige dieser Subtypen Veränderungen bekannt, die prognostisch von Bedeutung sind. Als prognostisch günstig gilt z.B. die Translokation t(15;17), welche zu 90\% bei der Promyelozytenleukämie (M3) auftritt. Eine prognostisch ungünstige zytogenetische Veränderung ist dagegen die Deletion del5q (Dierlamm et al., 2003; Lu et al., 2009).

\subsubsection{Myelodysplastisches Syndrom (MDS)}

Das MDS-Syndrom ist eine heterogen erworbene klonale Stammzellerkrankung, die durch quantitative und qualitative Veränderungen der Hämatopoese, durch periphere Zytopenie, durch eine Knochenmarkshyperplasie und häufig durch einen erhöhten 
Blastenanteil gekennzeichnet ist. Die Inzidenz dieser Erkrankung liegt bei 4-13 Erkrankungen pro 100000 Einwohner pro Jahr. Mit einem medianen Erkrankungsalter von 70 Jahren ist auch das MDS-Syndrom eine Erkrankung des fortgeschrittenen Erwachsenenalters. Unterschieden werden das primäre MDSSyndrom unklarer Genese (90\%) und das sekundäre MDS-Syndrom (10\%). Die Ätiologie des sekundären MDS-Sydroms ist in 90\% der Fälle durch eine chromosomale Aberration induziert, die nach vorangegangener Zytostatikatherapie (mit Alkylanzien, Topoisomerase-II-Inhibitoren, Cisplatin, Fludarabin) oder nach Radiatio bzw. kombinierter Radiochemotherapie auftreten kann. Zusätzlich sind auch organische Lösungsmittel wie Benzol ätiologisch relevant (Ciccone et al., 1993; Travis et al., 1994).

Die FAB-Klassifikation des MDS-Syndroms wird durch den unterschiedlichen Blastenanteil im Knochenmark bestimmt, der als wichtigster Prognosefaktor gilt. Tabelle 3 zeigt eine Übersicht dieser Subtypen mit ihren Charakteristika.

Anhand der Karyotypanalyse lassen sich weitere Unterschiede in der medianen Überlebenszeit erfassen. Unterschieden werden drei Gruppen von Anomalien im Karyotyp: der normale Karyotyp, der nicht-komplexe (eine oder zwei Chromosomenaberrationen) sowie der komplexe Karyotyp (drei oder mehr Chromosomenaberrationen). Mit einer medianen Überlebenszeit von 3,7 Monaten gilt der komplexe Karyotyp als prognostisch schlecht.

Chen $\mathrm{H}$ et al. (1996) konnten anhand einer Fall-Kontroll-Studie in den USA eine positive Korrelation des GSTT1-«null » Genotyps mit einem erhöhten MDS-Risiko zeigen. Als Ursache wurde eine verringerte Detoxifikation von Fremd- und endogenen Stoffen vermutet. Weitere in diesem Zusammenhang durchgeführte Untersuchungen in England und Deutschland konnten diese Ergebnisse nicht bestätigen (Basu et al., 1997; Atoyebi et al., 1997; Haase et al., 2002). 
Tabelle 3: FAB-Klassifikation des Myelodysplastischen Syndroms: (aus Herold, 2008, S. 94 )

\begin{tabular}{|c|c|c|c|c|}
\hline Subtyp & $\begin{array}{c}\text { Blasten- } \\
\text { anteil im } \\
\text { Knochen } \\
\text { mark }\end{array}$ & $\begin{array}{c}\text { Mediane } \\
\text { Überlebenszeit } \\
\text { (Monate) }\end{array}$ & $\begin{array}{c}\text { Zusätzliche } \\
\text { Veränderungen }\end{array}$ & $\begin{array}{c}\text { AML- } \\
\text { Übergang }\end{array}$ \\
\hline Refraktäre Anämie (RA) & $<5 \%$ & 40 & & $10 \%$ \\
\hline $\begin{array}{c}\text { Refraktäre Anämie mit } \\
\text { Ringsideroblasten (RARS) }\end{array}$ & $<5 \%$ & 37 & $\begin{array}{l}\quad>15 \% \\
\text { Ringsideroblasten } \\
\text { in Knochenmark }\end{array}$ & $11 \%$ \\
\hline $\begin{array}{c}\text { Refraktäre Anämie mit } \\
\text { Blastenüberschuss } \\
\text { (RAEB) }\end{array}$ & $5-19 \%$ & 12 & & $22 \%$ \\
\hline $\begin{array}{c}\text { RAEB in Transformation } \\
\text { (RAEB/T) }\end{array}$ & $20-29 \%$ & 5 & $\begin{array}{c}\text { fakultativ } \\
\text { Auerstäbchen }\end{array}$ & $35 \%$ \\
\hline $\begin{array}{l}\text { Chronische } \\
\text { myelomonozytäre } \\
\text { Leukämie (CMML): } \\
\text { •dysplastischer } \\
\text { Typ(<13000Leukozyten/ } \mu \mathrm{l}) \\
\text { •proliferativer } \\
\text { Typ( } \geq 13000 L e u k o z y t e n / \mu \mathrm{l})\end{array}$ & $<20 \%$ & 18 & $\begin{array}{l}\text { Periphere } \\
\text { Monozytose } \\
(>1000 / \mu 1)\end{array}$ & $12 \%$ \\
\hline
\end{tabular}

\subsubsection{Sekundäre Leukämien und MDS-Syndrom}

Akute Leukämien sind die häufigsten Therapie-assoziierten malignen Erkrankungen (Leone et al., 2001). Sie treten vermehrt nach Behandlung hämatologischer Erkrankungen wie Morbus Hodgkin, Non-Hodgkin-Lymphomen, Polycythaemia vera auf (Leone et al., 2001). Aber auch nach Therapie anderer Tumoren (Mammakarzinom, Hodentumor, Ovarialkarzinom) treten gehäuft sekundäre maligne hämatologische Neoplasien auf (Tallman et al., 1995; Karp und Smith, 1997; Leone et al., 2001).

Radiatio und Chemotherapie sind bekannte Ursachen für sekundäre Malignome, wobei die Inzidenz durch Kombination beider Therapieverfahren steigend ist (Leone 
et al., 2001). Dabei ist neben dem Patientenalter entscheidend, mit welcher kumulativen Dosis der vorangegangenen Chemotherapie und mit welcher Dosis an Bestrahlung die Patienten behandelt wurden (Levine und Bloomfield, 1992). Es gibt zusätzlich weitere interchemotherapeutische Unterschiede, so verfügt z.B. Melphalan über eine höhere leukämogene Potenz als Cyclophosphamid (Curtis et al., 1992). Insbesondere die Therapie-assoziierte akute myeloische Leukämie (t-AML) ist eine der häufigsten Langzeitkomplikationen nach durchgeführter Chemotherapie. Sie tritt oft auf, nachdem der Patient bereits das Stadium der Vollremission erreicht hat (Pedersen-Bjergaard, 1995). Es werden 10-20\% aller AML-Patienten zu den sekundär Erkrankten gerechnet (Karp und Smith, 1997).

Die Mehrheit der sekundären oder Therapie-assoziierten Leukämien durch Chemotherapeutika werden in 2 Gruppen unterteilt:

a) Leukämien nach Exposition mit Alkylanzien

b) Leukämien nach Exposition mit Topoisomerase-II-Inhibitoren.

Als alkylierende Substanzen werden unter anderem Cyclophosphamid, Chlorambucil, Ifosphamid verwendet. Die Leukämien treten mit einer Latenzzeit von zwei bis acht Jahren auf und sind vorrangig durch die Subtypen M1 und M2 gekennzeichnet (Leone et al., 2001). Zytogenetisch werden vorrangig folgende Veränderungen beobachtet: Deletion des Chromosoms 13, Verlust von Chromosom 5 und 7 (-5/-7) oder Partialdeletion des langen Arms beider Chromosomen (5q- und 7q-) und Chromosom-17p-Veränderungen mit p53-Allelverlust (Leone et al., 2001). Das Vorkommen der Deletionen nimmt mit zunehmender kumulativer Dosis an Alkylanzien zu (Pedersen-Bjergaard, 1995). Oft kommt es zu einer MDS-Vorphase mit unbalancierten Chromosomenaberrationen (Pedersen-Bjergaard und Rowley, 1994; Leone et al., 2001). Bei Hodgkin-Patienten beispielsweise steigt das kumulative Risiko exponentiell mit dem Alter und verhält sich direkt proportional zur kumulativen Dosis (Pedersen-Bjergaard et al., 1987).

Die Leukämieformen, die sich als Folge der Exposition mit Topoisomerase-IIHemmern entwickeln, treten im Vergleich mit einer Latenz von zwei Jahren wesentlich früher und vorrangig myelomonozytär und monozytär auf (Roman-Unfer et al., 1995; Leone et al., 2001). Etablierte Topoisomerase-II-Hemmer sind Doxorubicin, Epipodophyllotoxin und 4-Epidoxorubicin. Das Erkrankungsrisiko 
steigt auch hier mit zunehmender kumulativer Dosis des Agens und wird zusätzlich durch ein verkürztes Therapieintervall erhöht (Pedersen-Bjergaard, 1995). Die Zytogenetik dieser Leukämieformen umfasst balancierte Translokationen der Chromosomenbanden 11q23 (MLL-Gen) und 21q22 (Pedersen-Bjergaard und Rowley, 1994; Ben-Yehuda et al., 1996; Leone et al., 2001).

Eine Reihe von Untersuchungen zeigte, dass einerseits verschiedene Polymorphismen wie NAD(P)H:Chinonoxidoreduktase (Larson et al., 1999), Cytochrom-P450 3A4 (Felix et al., 1998) oder auch die unterschiedliche Aktivität von DNS-Reperaturgenen wie p53 auf Chromosom 17 (Ben-Yehuda et al., 1996) für ein gesteigertes sekundäres Leukämie- bzw. MDS-Risiko verantwortlich sein können.

\subsection{Beschreibung von Versuchsanordnung und Fragestellung der Arbeit}

Untersucht wurden Blut- und Knochenmarkproben von AML- und MDS-Patienten sowie von Kontrollpersonen in Bezug auf die von Coles et al. (2001b) beschriebene Sequenzvariation der GSTA1 an der Position -52.

Folgende drei Fragestellungen wurden geprüft:

1.) Gibt es einen Unterschied zwischen AML- bzw. MDS-Patienten und gesunden Kontrollpersonen in Bezug auf den GSTA1-Genotyp?

2.) Lässt sich ggf. ein Unterschied in bestimmten FAB-Subgruppen feststellen ?

3.) Gibt es einen Unterschied zwischen Patienten mit Therapie-induzierter AML/ Therapie-induziertem MDS und gesunden Kontrollpersonen in Bezug auf den GSTA1-Genotyp? 


\section{Material und Methoden}

\subsection{Material}

\subsubsection{Geräte}

- Autoklav

Autoklav 23, MELAG

- Thermocycler

Eppendorf Mastercycler gradient

- Elektrophorese-Apparaturen

Horizontalgelelektrophorese mit 20er Kämmen, Bio Rad

- UV-Transilluminator

Gel Doc 1000, Bio Rad und Kamerasystem

- Zentrifugen

Tischzentrifuge: Biofuge picoHeraeus Instruments; Beckman GS-15R Zentrifuge

- Zentrifugenrohre steril mit konischem Boden, Sarstedt

- Wärmebad

GLF-Wärmebad

- Mikropipetten 3fach: 0,5-10 $\mu 1,10-100 \mu 1$, 100-1000 $\mu 1$, Eppendorf Reference

- Wärmeschrank

Memmert Typ U 10

- Vortex-2 genie

Scientific Industries SI

- Photometer mit Quarzküvettensatz

Uvikon 922 Spectrophotometer, Kontron Instruments

- Mikrowelle

MWS 2819; Bauknecht

- Computer

Gateway 2000

- Drucker

HP-Laserjet 5 L; Mitsubishi

Digital Colour Printer CP-D1E

- Reaktionsgefäße

Eppendorfcups der Größe:

$0,5 \mathrm{ml}$ und $1,5 \mathrm{ml}$

- Waage

MC1, Analytic AC 210S, Sartorius $\mathrm{AG}$

- Wasserfiltrationsanlage

Milli-Q Plus, Millipore

Sämtliche Pipettenspitzen und Reaktionsgefäße wurden vor Gebrauch autoklaviert. 


\subsubsection{Reagenzien}

- dNTP (15 mM)

MBI Fermentas

- Primer: AF4, AR1 (jeweils 100pmol/ $\mu \mathrm{l}$ ) Eurogentec

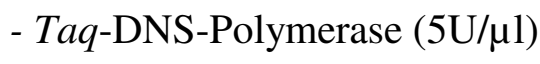

Promega Corporation, Madison, USA

- Kb-DNS-Ladder

Invitrogen Life Technologies

- Taq-Poly-Buffer (10x)

Promega Corporation, Madison, USA

- Ear I (10000U/ml)

New England Bio Laps

- NE-Buffer 1:

$10 \mathrm{mM}$ Bis Tris Propane- $\mathrm{HCl}$ $10 \mathrm{mM} \mathrm{MgCl} 2$

$1 \mathrm{mM}$ DTT

pH: 7,0

- Milli Q-Wasser

Milli-Q Plus, Millipore

\subsubsection{Chemikalien}

- Agarose

Seakem LE Agarose; BMA

- VE-Wasser

Purification Pak, Millipore

- Ethidiumbromid

$10 \mathrm{mg} / \mathrm{ml}$

- Auftragelösung

$50 \%$ Glycerin

$0,1 \%$ Bromphenolblau

0,1\% Xylenzyanol

49,8\% Wasser

Die Lagerung erfolgt bei $4^{\circ} \mathrm{C}$

- SDS-Pulver

Natriumdodecylsulfat, Fluka,

BioChemika

- SDS-Lösung

10\%ig, 10 g SDS-Pulver gelöst in $100 \mathrm{ml}$ Wasser

- Proteinase K

$2 \mathrm{mg} / \mathrm{ml}$ spezifische Aktivität:

38 mAnson unit/mg, Promega

- Lyse-Puffer

$10 \mathrm{mM} \mathrm{KHCO}_{3}$

$155 \mathrm{mM} \mathrm{NH}_{4} \mathrm{Cl}$

$0,1 \mathrm{mM}$ EDTA

$\mathrm{pH}=7,4$

Die Lagerung erfolgt bei $4^{\circ} \mathrm{C}$ 
- Lösung 2

- Kochsalzlösung

- TE-Puffer

- Ethanol 100\%

- Ethanol $70 \%$

- TBE-Puffer (5x)
$50 \mathrm{mM}$ Tris-HCl

$20 \mathrm{mM}$ EDTA

$2 \%$ SDS

$\mathrm{pH}=8,0$

Die Lagerung erfolgt bei

Raumtemperatur

$6 \mathrm{M} \mathrm{NaCl-Lösung}$

Die Lagerung erfolgt bei $4^{\circ} \mathrm{C}$

$10 \mathrm{mM}$ Tris- $\mathrm{HCl}$

$1 \mathrm{mM}$ EDTA

$\mathrm{pH}=7,4$

$70 \mathrm{ml} \mathrm{100 \%}$ Alkohol

$30 \mathrm{ml}$ autoklaviertes Wasser

$27 \mathrm{~g}$ Tris

13,75 g Borsäure

1,86 g EDTA

$\mathrm{pH}=8,3$

Die Lagerung erfolgt bei

Raumtemperatur

\subsection{Methoden}

\subsubsection{DNS-Isolierung aus Vollblut}

Für diese Untersuchung wurden pseudonymisierte DNS-Proben von Patienten und gesunden Personen verwendet, von denen folgende Informationen bekannt waren: Geschlecht und Alter zum Zeitpunkt der Probennahme, bei Patienten waren zusätzlich die Informationen zur Diagnose und - nicht in allen Fällen - zur FABKlassifizierung sowie zur Karyotypanalyse verfügbar. Im Folgenden wird die Aufarbeitung der Blutproben beschrieben: Als Ausgangsmaterial für die Isolation genomischer DNS diente Vollblut, welches zuvor in EDTA-Monovetten (der Firma Sarstedt für Blutvolumina von $2 \mathrm{ml}$ ) gesammelt wurde. Zunächst wurden die Zellen mit dem hypotonen Lyse-Puffer versetzt und ca. 90 Minuten auf Eis inkubiert. Hierdurch wurden die Erythrozyten selektiv lysiert.

Die Stabilität der Leukozyten wurde nicht beeinträchtigt, so dass diese durch Zentrifugation bei $600 \mathrm{x}$ g wiedergewonnen werden konnten. Das Zellpellet wurde dann erneut mit 5ml Lyse-Puffer gewaschen und anschließend mit $5 \mathrm{ml}$ der Lösung 2 
versetzt. Die in dieser Lösung enthaltene SDS-Lösung bewirkte die Auflösung der Leukozytenmembran. Daran anschließend erfolgte die Inkubation mit $150 \mu 1$ Proteinase $\mathrm{K}$ für mindestens 1 Stunde bei $56^{\circ} \mathrm{C}$. Während dieser Zeit wurden die Leukozytenproteine verdaut. Nach Zugabe von 1,5 ml $6 \mathrm{M} \mathrm{NaCl-Lösung} \mathrm{wurde} \mathrm{die}$ Probe zunächst für sechs Sekunden gevortext und anschließend 15 Minuten bei Raumtemperatur mit mindestens 5000 x g zentrifugiert. Die DNS konnte im Anschluss daran nach Überführung in ein Ethanol-beständiges Gefäß (Sarstedt Zentrifugenrohre für $50 \mathrm{ml}$ Volumen, steril mit konischem Boden), durch Zugabe von 1,5x Vol 100\%igem Ethanol gefällt werden. Diese sollte nach der Fällung gut sichtbar als Faden in der Lösung schwimmen. In zwei weiteren Schritten wurde das DNS-Pellet in 70\%igem Ethanol (ca. $500 \mu \mathrm{l}$ ) gewaschen und danach bei $56^{\circ} \mathrm{C}$ getrocknet. Die Lösung und Lagerung der DNS erfolgte in $1 x$ TE-Puffer (bei $4^{\circ} \mathrm{C}$ ), je nach Pelletgröße in ca. 300-500 $\mu 1$ Lösung.

\subsubsection{DNS-Konzentrations- und Reinheitsbestimmung}

Die Konzentration und Reinheit der isolierten DNS wurde im Photometer (Uvikon 922 Spectrophotometer, Kontron Intruments) bestimmt. Die optische Dichte (Extinktion) einer 1:100 Verdünnung in 1x TE-Puffer wurde bei einer Wellenlänge von $\lambda=260 \mathrm{~nm}$, dem Absorptionsmaximum von Nukleinsäuren sowie bei $280 \mathrm{~nm}$ (Absorptionsmaximum vieler Aminosäuren) gemessen. Demnach befanden sich in einer Quarzküvette (Schichtdicke $1 \mathrm{~cm}$ ) $10 \mu 1$ gelöste DNS zusammen mit $990 \mu 1$ 1x TE-Puffer. Der Wert der $\mathrm{OD}_{280}$ erfasst alle wesentlichen Verunreinigungen. Das Lösungsmittel diente als Referenz. Eine $\mathrm{OD}_{260}$ von 1 entspricht bei doppelsträngiger DNS einer Konzentration von $50 \mu \mathrm{g} / \mathrm{ml}$. Aus dieser Beziehung ergibt sich folgende Formel für die Berechnung der Konzentration:

$$
\mathrm{C}=\mathrm{E} \times 50 \mu \mathrm{g} / \mathrm{ml} \times \mathrm{V}
$$

( $\mathrm{C}=$ DNS-Konzentration; E=Extinktion; V=Verdünnungsfaktor)

Ein $\mathrm{Ma} ß$ für die Reinheit der DNS ist der Quotient aus $\mathrm{OD}_{260}$ und $\mathrm{OD}_{280}$, welcher bei allen Proben zusätzlich bestimmt wurde. Für proteinfreie DNS liegt der Wert zwischen 1,8 und 2,0. Ein geringerer Wert deutet auf Verunreinigungen hin. 


\subsubsection{Polymerase-Ketten-Reaktion (PCR)}

Mithilfe der PCR kann man einen bestimmten DNS-Bereich gezielt vervielfältigen.

Durch Erhitzen der doppelsträngigen DNS auf $95^{\circ} \mathrm{C}$ (Denaturierung) erhält man einzelsträngige DNS-Matritzen. Man benötigt zwei komplementäre Oligonukleotide (Primer), die zuvor so synthetisiert wurden, dass sie spezifisch mit dem Start- bzw. Endpunkt der gewünschten Sequenz hybridisieren (annealing). Mithilfe des thermostabilen Enzyms Taq-DNS-Polymerase (aus dem Bakterium Thermophilus aquaticus) und den vier Desoxynukleotiden (dATP, dGTP, dCTP, dTTP) kann die Doppelstrangsynthese erfolgen. Dabei wird der Reaktionsansatz auf eine für die Primer günstige Hybridisierungstemperatur $\left(60^{\circ} \mathrm{C}\right)$ abgekühlt. Dadurch kann die Spezifität der Oligonukleotidbindung an die Zielsequenz erhöht werden. Die Primer lagern sich an den zu amplifizierenden DNS-Abschnitt an und bilden somit eine doppelsträngige Startstelle. Nach Erhitzen auf $72^{\circ} \mathrm{C}$ kann dort die enzymatische Verlängerungsreaktion mithilfe der Taq-DNS-Polymerase beginnen (DNS-Synthese, Polymerisierung). Als PCR-Produkt erhält man eine doppelsträngige DNS. Der Reaktionsablauf in jeweils einem Zyklus besteht somit aus 3 Teilen: Denaturieren, Hybridisieren (annealing), und DNS-Synthese (Polymerisieren). In jedem Zyklus wird die Zielsequenz verdoppelt und liegt am Ende der gesamten Reaktion in exponentieller Anzahl vor.

Ein Reaktionsansatz setzt sich wie folgt zusammen:

$$
\begin{aligned}
& \text { 0,25 } \mu \mathrm{l} \text { Primer 1: GST-AF } 4(100 \mathrm{pmol} / \mu \mathrm{l}) \\
& 0,25 \mu \mathrm{l} \text { Primer 2: GST-AR } 1(100 \mathrm{pmol} / \mu \mathrm{l}) \\
& 0,75 \mu \mathrm{l} \quad \operatorname{dNTP}(15 \mathrm{mM}) \\
& 3 \mu \mathrm{l} \text { 10x Taq-Puffer } \\
& \text { 24,6 } \mu 1 \quad \text { Milli Q-Wasser } \\
& 0,2 \mu \mathrm{l} \quad \text { Promega Taq-Polymerase (5 U/ } \mu \mathrm{l})
\end{aligned}
$$

$29,05 \mu \mathrm{l}$ Gesamtansatz wurden zusammen mit jeweils $200 \mathrm{ng}$ DNS in ein 0,5 ml Eppendorfgefäßcup pipettiert. Als Negativkontrolle diente ein Ansatz ohne DNS. 
Die Reaktion fand in einem Thermocycler (Eppendorf Mastercycler gradient) statt. Anschließend wurden die PCR-Produkte in einem 1,5\%igem Agarosegel elektrophoretisch aufgetrennt (siehe 2.2.4).

Die Primer wurden von der Firma Eurogentec synthetisiert, lyophilisiert und mit Angaben der Konzentration geliefert. Das Lyophilisat wurde mit 1x TE-Puffer $(\mathrm{pH}=8)$ gelöst und die Gebrauchslösung auf $100 \mathrm{pmol} / \mu 1$ eingestellt.

Primersequenzen:

AF4: $\quad 5$-TGT-TGA-TTG-TTT-GCC-TGA-AAT-T-3

AR1: 5 -GTT-AAA-CGC-TGT-CAC-CGT-CCT-3`

(Coles et al., 2001b)

Es ergab sich eine Produktlänge von 480bp (Coles et al., 2001b).

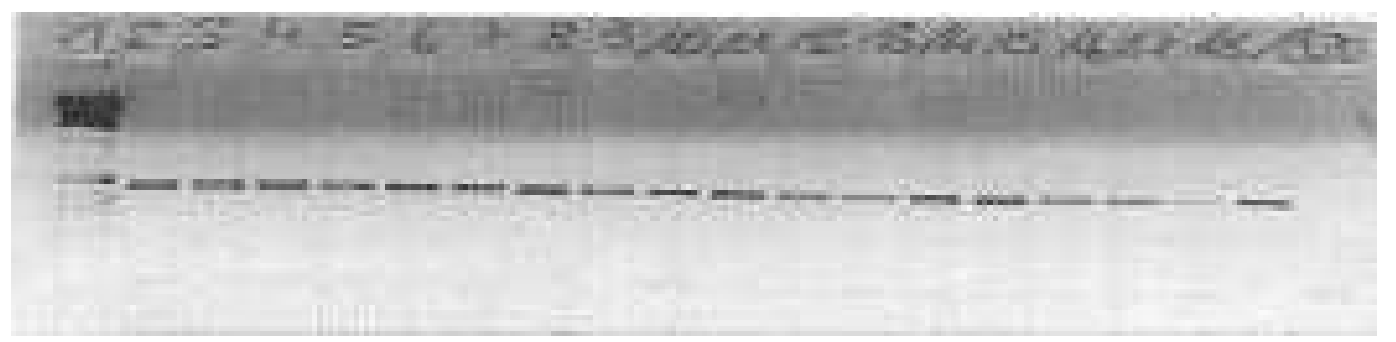

Abbildung 1: Darstellung des PCR-Produktes der GSTA1-Amplifikation. Es wurden 18 verschiedene Proben aufgetragen (je 200 ng DNS) sowie eine Leerprobe, die Wasser an Stelle von DNS enthielt. Links wurde eine Kb-Leiter aufgetragen, um eine Kontrolle der Größe der PCR-Produkte durchzuführen. 
Temperaturprofil:

$\begin{array}{cccc}\text { Denaturierung } & 95^{\circ} \mathrm{C} & 4 \mathrm{~min} & 1 \text { Zyklus } \\ \text { Amplifizierungszyklen } & 94^{\circ} \mathrm{C} & 1 \mathrm{~min} & \\ & 60^{\circ} \mathrm{C} & 1 \mathrm{~min} & 35 \text { Zyklen } \\ & 72^{\circ} \mathrm{C} & 1 \mathrm{~min} & \\ \text { Abschluss } & 72^{\circ} \mathrm{C} & 10 \mathrm{~min} & 1 \text { Zyklus } \\ & 4^{\circ} \mathrm{C} & \text { unendlich } & \end{array}$

\subsubsection{Agarose-Gelelektrophorese}

Zur Auftrennung der PCR-Produkte wurde eine Agarose-Gelelektrophorese durchgeführt. 1,5 g Agarose wurden mit $100 \mathrm{ml}$ VE-Wasser in Lösung gebracht. Diese wurde kurz aufgekocht, mit $2 \mu$ l Ethidiumbromid versetzt und auf einen Gelschlitten gegossen. Aus dem PCR-Produkt wurden jeweils $5 \mu l$ entnommen und mit 0,5 $\mu \mathrm{l}$ Auftragspuffer in die Geltaschen pipettiert. Bei einer konstanten Spannung von $100 \mathrm{~V}$ konnte die Auftrennung der DNS-Fragmente erfolgen. Dies ist möglich, da DNS-Moleküle aufgrund ihrer negativen Ladung zur Kathode wandern. Als Größenstandard diente eine 1-Kb-DNS-Leiter. Zur Auswertung wurde das Gel auf einen UV-Leuchttisch gelegt. Dabei wurde die Fluoreszenz des in den DNS-Banden angereicherten Ethidiumbromid mit Breitband UV-Anregung (290-365nm) gemessen und das Bandenmuster anschließend mit der Geldokumentation ausgewertet und ausgedruckt.

\subsubsection{Restriktionsenzymverdau}

Unter restriktionsenzymatischem Verdau versteht man das Zerteilen von DNS mithilfe spezifischer Enzyme an definierten Sequenzen. Diese Restriktionsendonukleasen sind in der Lage spezifisch an doppelsträngiger DNS zu binden und können dabei an oder in der Nähe der Erkennungssequenz schneiden. Die entstehenden fragmentierten Produkte können anschließend ihrer Größe entsprechend gelelektrophoretisch aufgetrennt werden. Dabei wird die Wanderungsgeschwindigkeit durch die Länge der einzelnen Fragmente beeinflusst. Zunächst wurden die jeweiligen Amplifikatkonzentrationen unter Berücksichtigung des Bandenmusters der PCR-Reaktion ermittelt. Der Stärke ihrer Banden 
entsprechend gingen diese mit 17,5 $\mu 1,15 \mu 1$ oder $10 \mu \mathrm{l}$ in die Verdaureaktion ein. Um gleiche Volumina zu gewährleisten, wurden die 15- $\mu$ l-Reaktionsansätze mit 2,5 $\mu \mathrm{l}$ und die 10- $\mu$ l-Reaktionsansätze mit 7,5 $\mu \mathrm{l}$ Milli Q-Wasser verdünnt. Anschließend wurden den Ansätzen jeweils $2 \mu$ l Enzympuffer und 0,4 $\mu$ l (4 U) Restriktionsenzym hinzugefügt.

Im einzelnen handelte es sich um:

NE-Buffer 1: $10 \mathrm{mM}$ Bis Tris Propan-HCl

$10 \mathrm{mM} \mathrm{MgCl} 2$

$1 \mathrm{mM}$ Dithiothreitol

pH: 7,0

Enzym: Ear I (10000 U/ml)

Die Aktivität einer Restriktionsendonuklease wird wie folgt definiert: 1 Unit ist die Enzymaktivität, die $1 \mu \mathrm{g}$ Lambda $\mathrm{DNS}$ bei $37^{\circ} \mathrm{C}$ in einer Stunde in einem Gesamtvolumen von $50 \mu 1$ vollständig spaltet. Die Ansätze enthielten jeweils $4 \mathrm{U}$ an Restriktionsenzym. Sie wurden über Nacht bei der enzymspezifischen Temperatur von $37^{\circ} \mathrm{C}$ im Wärmeschrank inkubiert und anschließend entsprechend der Fragmentgröße in einen 1,5\%igen Agarosegel elektrophoretisch aufgetrennt (siehe Agarose-Gelelektrophorese).

Ear I stammt aus Enterobacter aerogenes und erkennt spezifisch die Sequenz:

$$
\begin{aligned}
& 5 \text {....CTCTTC(N) } 1 \downarrow \ldots 3 \\
& 3^{`} \ldots \text {...GAGAAG(N) } 4 \uparrow \ldots 5
\end{aligned}
$$

Damit ergaben sich Produktlängen von entweder 480bp oder 380bp+100bp (Coles et al., 2001b). 


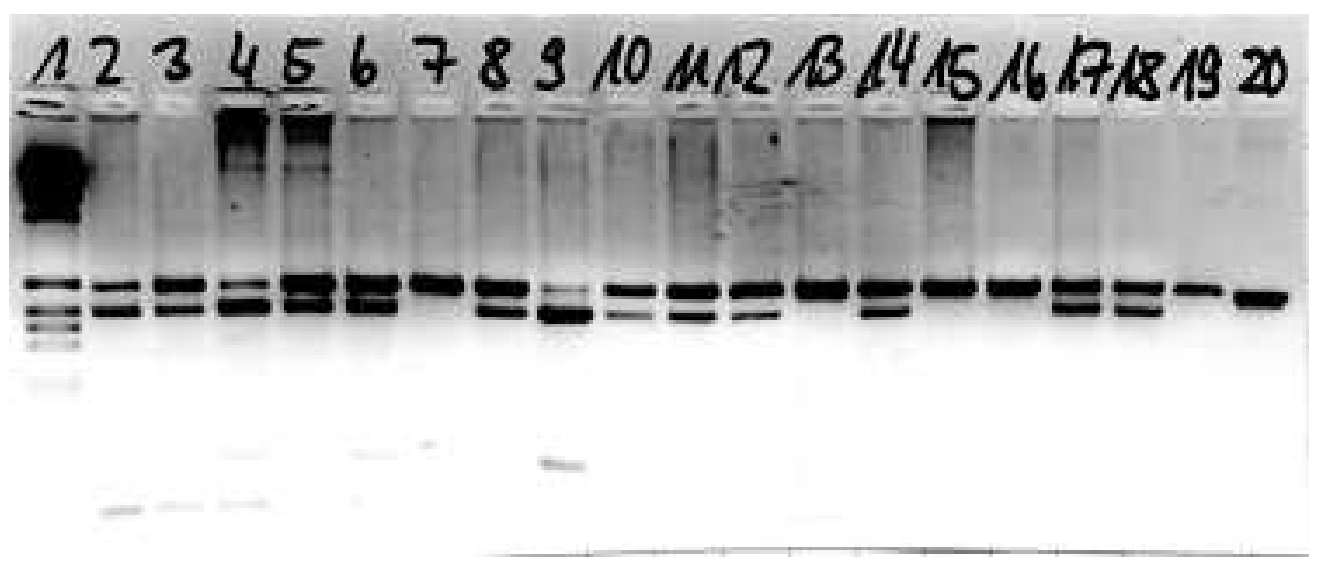

Abbildung 2: Ergebnis des Restriktionsverdaus mit Ear I.

Auf Bahn 1 wurde die Kb-Leiter aufgetragen, auf den Bahnen 2 bis 20 wurden Proben des Restriktionsverdaus aufgetragen. Klar erkennbar sind die Banden bei 480 bp und 380 bp. Proben, die nur eine Bande bei 480 bp zeigten, wiesen den homozygoten Genotyp GSTAl*A auf, während Proben, die sowohl bei $380 \mathrm{bp}$ als auch bei 480 bp Banden aufwiesen, als heterozygot für die $G S T A 1 * A$ und $G S T A 1 * B$ eingestuft wurden. Lag eine starke Bande bei 380 bp und eine schwache Bande bei 480 bp vor (siehe Bahn 4 und Bahn 9), dann wurde die Probe als homozygot für GSTA $1 * B$ eingestuft.

\subsubsection{Karyotypanalyse}

Die Karyotypanalyse wurde von Herrn PD Dr. med. Detlef Haase in der Hämatologischen Abteilung der Universität Göttingen durchgeführt.

Es konnten 3 unterschiedliche Karyotypen erfasst werden.

Unterschieden wurden der normale Karyotyp, der nicht-komplexe (NK) und der komplexe Karyotyp. Dabei beinhaltet der nicht-komplexe Karyotyp ein bis zwei und der komplexe Karyotyp drei oder mehr Chromosomenaberrationen. 


\subsection{Statistische Auswertung}

Die erhobenen Daten werden im Ergebnisteil tabellarisch in absoluten Zahlen und prozentual aufgeführt. Für die Testung der statistischen Signifikanz wurde der zweiseitige Fisher's exakte Test mit einem Signifikanzniveau von 5\% durchgeführt. Es wurde die Software „Stat Xact“, Version 6.1 verwendet. 


\section{Ergebnisse}

\subsection{Einführung}

Als Untersuchungsmaterial standen DNS-, Blut- und Knochenmarkproben pseudonymisierter hämatologischer Patienten bzw. Blutproben eines pseudonymisierten Kontrollkollektivs zur Verfügung. Der größte Teil der Proben der hämatologischen Patienten wurde in der Abteilung für Hämatologie und Onkologie der Universität Göttingen bezüglich des Karyotyps analysiert. In der Abteilung Arbeits- und Sozialmedizin erfolgte die Genotypisierung auf den GSTA1-Genotyp.

Definiert sind drei verschiedene Genotypvarianten in der GSTA1-Promotorregion: homozygot $h G S T A l * A$, heterozygot $h G S T A l * A / B$ und homozygot $h G S T A l * B$. Insgesamt wurden 293 AML-Patienten und 189 MDS-Patienten untersucht. Es konnte in der AML-Subgruppe bei 200 Patienten der Genotyp und bei 176 der Karyotyp ermittelt werden. In der MDS-Subgruppe liegt von 188 Patienten der Genotyp und von 177 der Analysierten der Karyotyp vor (siehe Tabelle 4).

Tabelle 4: Zusammenstellung der an den Untersuchungen teilgenommenen Patienten.

\begin{tabular}{|c|c|c|c|}
\hline & Gesamt & $\begin{array}{c}\text { Ergebnis } \\
\text { Genotyp }\end{array}$ & $\begin{array}{c}\text { Ergebnis } \\
\text { Karyotyp }\end{array}$ \\
\hline AML & 293 & 200 & 176 \\
\hline MDS & 189 & 188 & 177 \\
\hline
\end{tabular}

\subsection{Genotypgesamtübersicht}

Das in die Genotypanalyse eingeschlossene Kontrollkollektiv umfasste 231 Individuen. $33,8 \%$ dieser Untersuchten waren homozygot für die $h G S T A l^{*} A$ Variante, die Mehrheit war heterozygot mit 54,1\% und 12,1\% waren homozygot für die $h G S T A l * B$-Variante. In der AML- und MDS-Gruppe unterschieden sich die Prozentwerte für die homozygote $h G S T A l * A$ - bzw. die heterozygote Variante unwesentlich. 
In beiden Fällen lagen die Werte zwischen $40 \%$ und 50\%. Für 11,7\% der Untersuchten in der AML-Gruppe ergab sich der homozygote $h G S T A l * B$-Genotyp, wohingegen in der MDS-Gruppe nur 9,5\% diesen Genotyp aufwiesen (siehe Tabelle 5).

Tabelle 5: Genotypgesamtverteilung.

(N entspricht der Gesamtzahl der Untersuchten; für die jeweiligen Genotypen können der Tabelle die Anzahl der Individuen, sowie die dazugehörigen Prozentwerte entnommen werden; dieser Aufbau gilt auch für die nachfolgenden tabellarischen Darstellungen)

\begin{tabular}{|c|c|c|c|c|c|c|c|}
\hline & N & $\boldsymbol{h G S T A 1} * \boldsymbol{A}$ & in \% & $\boldsymbol{h G S T A 1} * \boldsymbol{A} \boldsymbol{B}$ & in \% & $\boldsymbol{h G S T A 1} *^{\boldsymbol{B}}$ & in \% \\
\hline Kontrolle & 231 & 78 & $\mathbf{3 3 , 8}$ & 125 & $\mathbf{5 4 , 1}$ & 28 & $\mathbf{1 2 , 1}$ \\
\hline AML & 200 & 92 & $\mathbf{4 6}$ & 89 & $\mathbf{4 4 , 5}$ & 19 & $\mathbf{9 , 5}$ \\
MDS & 188 & 81 & $\mathbf{4 3 , 1}$ & 85 & $\mathbf{4 5 , 2}$ & 22 & $\mathbf{1 1 , 7}$ \\
\hline
\end{tabular}

\subsection{AML-Zytogenetik}

Die Zytogenetik untersucht Veränderungen des genetischen Materials und deren Auswirkungen auf die Zellen. Die Aufschlüsselung der AML-Zytogenetik lieferte genotypische Unterscheidungen der in Kapitel 2.2.6 (S.21) erläuterten Karyotypen. Insgesamt wurden 176 AML-Patienten karyotypisiert und anschließend im Hinblick auf die GSTA1-Genotypverteilung analysiert.

Im Bereich des komplexen Karyotyps konnten folgende Werte erfasst werden: 53,3\% für den homozygoten $h G S T A l * A$-Genotyp, $40 \%$ für den heterozygoten $h G S T A l * A / B$-Genotyp und 6,7\% wurden für den homozygoten $h G S T A l * B$-Genotyp ermittelt. Die Prozentzahlen des nicht-komplexen (NK), sowie des normalem Karyotyps waren ähnlich in der gesamten Genotypverteilung. Für den homozygoten $h G S T A l * B$-Genotyp wurde weder eine signifikante Erhöhung noch eine signifikante Erniedrigung verzeichnet. Eine Übersicht dieser Zahlen zusammen mit den Zahlen des Kontrollkollektivs als Referenz ist Tabelle 6 zu entnehmen. 
Tabelle 6: Prozentzahlen aus dem Bereich AML-Zytogenetik.

\begin{tabular}{|c|c|c|c|c|c|c|c|}
\hline & N & $\boldsymbol{h G S T A 1}$ *A & in \% & $\boldsymbol{h G S T A 1}$ *A/B & in \% & $\boldsymbol{h G S T A 1} *_{\boldsymbol{B}} \boldsymbol{\text { in \% }}$ \\
\hline Kontrolle & 231 & 78 & $\mathbf{3 3 , 8}$ & 125 & $\mathbf{5 4 , 1}$ & 28 & $\mathbf{1 2 , 1}$ \\
\hline Komplex & 45 & 24 & $\mathbf{5 3 , 3}$ & 18 & $\mathbf{4 0}$ & 3 & $\mathbf{6 , 7}$ \\
NK & 62 & 24 & $\mathbf{3 8 , 7}$ & 30 & $\mathbf{4 8 , 4}$ & 8 & $\mathbf{1 2 , 9}$ \\
Normal & 69 & 29 & $\mathbf{4 2}$ & 32 & $\mathbf{4 6 , 4}$ & 8 & $\mathbf{1 1 , 6}$ \\
\hline
\end{tabular}

$\mathrm{NK}=$ nicht-komplex

\subsection{MDS-Zytogenetik}

Es wurden insgesamt 177 der MDS- Erkrankten karyotypisiert. Dabei wurde für den komplexen Karyotyp der MDS-Subgruppe mit 3,3\% ein vergleichsweise niedriger Wert für den $h G S T A l * B$-Genotyp verzeichnet. Die Mehrzahl der Patienten des genannten Karyotyps fanden sich mit 63,3\% im heterozygoten Bereich und 33,3\% ergaben sich für den $h G S T A l * A$-Genotyp. Auch bildeten die Untersuchten des nichtkomplexen Karyotyps mit 44,9\% ihre Mehrheit im heterozygoten Bereich. 40,6\% waren homozygot $h G S T A l * A$ und ein leicht erhöhter Wert $(14,5 \%)$ konnte für den $h G S T A 1 * B$-Genotyp erfasst werden. Für den normalen Karyotyp ließen sich bei dem homozygoten $h G S T A l * B$-Genotyp keine signifikanten Erniedrigungen oder Erhöhungen finden. Die Werte lagen dort bei $48,7 \%$ für $h G S T A l * A, 39,8 \%$ für die heterozygote Variante und $11,5 \%$ für $h G S T A l * B$.

Die Übersicht darüber liefert Tabelle 7. 
Tabelle 7: Genotypverteilung aus dem Bereich der MDS-Zytogenetik.

\begin{tabular}{|c|c|c|c|c|c|c|c|}
\hline & $\mathrm{N}$ & $h G S T A I * A$ & in $\%$ & $h G S T A 1 * A / B$ & in $\%$ & $h G S T A 1 * B$ & in $\%$ \\
\hline Kontrolle & 231 & 78 & 33,8 & 125 & 54,1 & 28 & 12,1 \\
\hline Komplex & 30 & 10 & 33,3 & 19 & 63,3 & 1 & 3,3 \\
\hline NK & 69 & 28 & 40,6 & 31 & 44,9 & 10 & 14,5 \\
\hline Normal & 78 & 38 & 48,7 & 31 & 39,8 & 9 & 11,5 \\
\hline
\end{tabular}

$\mathrm{NK}=$ nicht-komplex

\subsection{FAB-Klassifikation der AML-Subgruppe}

Tabelle 8 zeigt die Genotypverteilung der AML-Subgruppe unter Berücksichtigung der FAB-Klassifikation. Die FAB-Klassifikation (French-American-British-Group) der AML trifft die Unterscheidung der Erkrankung nach morphologischen Kriterien (Chromatinstruktur, Kernform, Nukleolen, Zellgröße, Zytoplasma, Vakuolisierung). Die einzelnen Subtypen sind der Einleitung unter 1.3.2 (S. 8) zu entnehmen. Die Gesamtzahl der FAB-klassifizierten AML-Patienten war 83, wobei die Anzahl der Erkrankten der Subtypen M0, M3, M4, M5, M6 und M7 vergleichsweise gering ausfiel. Aufgrund der geringen Fallzahlen wurde für diese Subgruppen von einer statistischen Auswertung abgesehen. Das ist im Hinblick auf die Prozentverteilung zu berücksichtigen, denn aus diesen Bereichen konnten unter anderem erhöhte Werte für den $h G S T A l * B$-Genotyp ermittelt werden. Beispielsweise konnten 28,6\% für M0, 22,2\% für M6 oder auch 20\% für den M4-Subtyp des genannten Genotyps erfasst werden. Die Mehrzahl der Untersuchten konnte morphologisch der AML mit (M2)- bzw. ohne Ausreifung (M1) zugeordnet werden. Von 20 Patienten des M1Subtyps wurde bei $50 \%$ der heterozygote $h G S T A l * A / B$-Genotyp ermittelt, $45 \%$ waren homozygot $h G S T A l^{*} A$ und nur $5 \%$ waren homozygot $h G S T A l * B$. Hingegen ergab sich für den M2-Subtyp von 30 Untersuchten ein Wert von $50 \%$ für den homozygoten $h G S T A l * A$-Genotyp, $36,6 \%$ waren heterozygot und für den homozygoten $h G S T A l * B$-Genotyp konnte ein Wert von 13,4\% verzeichnet werden.

Eine detaillierte Zusammenstellung dieser Ergebnisse findet sich in Tabelle 8. 
Tabelle 8: Prozentverteilung der AML-FAB-Klassifikation.

(M4 (EO): akute myelomonozytäre Leukämie mit Eosinophilie; M5 (a,b): undifferenzierte und differenzierte akute monozytäre Leukämie)

\begin{tabular}{|c|c|c|c|c|c|c|c|}
\hline & $\mathrm{N}$ & $h G S T A 1 * A$ & in $\%$ & $h G S T A 1 * A / B$ & in $\%$ & $h G S T A 1 * B$ & in $\%$ \\
\hline Kontrolle & 231 & 78 & 33,8 & 125 & 54,1 & 28 & 12,1 \\
\hline M0 & 7 & 3 & 42,8 & 2 & 28,6 & 2 & 28,6 \\
\hline M1 & 20 & 9 & 45 & 10 & 50 & 1 & 5 \\
\hline M2 & 30 & 15 & 50 & 11 & 36,6 & 4 & 13,4 \\
\hline M3 & 6 & 2 & 33,3 & 3 & 50 & 1 & 16,7 \\
\hline M4 (EO) & 5 & 0 & $\mathbf{0 , 0}$ & 4 & 80 & 1 & 20 \\
\hline M5 (a,b) & 3 & 3 & 100 & 0 & $\mathbf{0 , 0}$ & 0 & $\mathbf{0 , 0}$ \\
\hline M6 & 9 & 3 & 33,3 & 4 & 44,4 & 2 & 22,2 \\
\hline M7 & 3 & 1 & 33,3 & 2 & 66,7 & 0 & $\mathbf{0 , 0}$ \\
\hline
\end{tabular}

\subsection{FAB-Klassifikation der MDS-Subgruppe}

Der unterschiedliche Blastenanteil im Knochenmark, der wichtigste Prognosefaktor des MDS-Syndroms, wird zur FAB-Klassifikation herangezogen. Genauere Angaben dazu finden sich in der Einleitung unter Punkt 1.3.3 (S. 8).

Insgesamt wurden 146 mit dem MDS-Syndrom erkrankte Patienten klassifiziert. 55 dieser Erkrankten wiesen entsprechend ihrem Blastenanteil eine refraktäre Anämie auf. 36,4\% dieses Subtyps waren homozygot für die $h G S T A l * A$-Variante, 43,6\% waren heterozygot und ein Wert von 20\% konnte im Bereich des homozygoten $h G S T A 1 * B$-Genotyps erfasst werden. Von 26 analysierten refraktären Anämieträgern mit Ringsideroblasten waren $46,1 \%$ homozygot $h G S T A l * A, \quad 38,5 \%$ waren heterozygot und $15,4 \%$ homozygot $h G S T A l * B$. Als CMML-Erkrankte wurden insgesamt 12 Patienten klassifiziert. Unter ihnen wiesen $50 \%$ den $h G S T A l * A$ Genotyp auf, 41,7\% waren heterozygot und 8,3\% konnten im Bereich des homozygoten $h G S T A l * B$-Genotyps ermittelt werden. 35 Patienten konnten dem 
RAEB-Subtyp zugeordnet werden, wobei die Mehrheit jener Untersuchten den heterozygoten Genotyp aufwiesen (48,6\%). Mit 42,8\% konnten Träger des $h G S T A l * A$-Genotyps des genannten Subtyps erfasst werden und eine Zahl von 8,6\% ergab sich für den homozygoten $h G S T A l * B$-Genotyp. Im Bereich des RAEBSubtyps in Transformation wiesen von 18 der Erkrankten $61,1 \%$ den heterozygoten Genotyp auf, 33,3\% der Patienten waren homozygot für die $h G S T A l * A$-Variante und $5,6 \%$ wurden für den $h G S T A l * B$-Genotyp erfasst.

Eine Zusammenstellung dieser Ergebnisse liefert Tabelle 9.

Tabelle 9: Übersicht der FAB-klassifizierten MDS-Patienten.

\begin{tabular}{|c|c|c|c|c|c|c|c|}
\hline & $\mathrm{N}$ & $h G S T A 1 * A$ & in $\%$ & $h G S T A ! * A / B$ & in $\%$ & $h G S T A 1 * B$ & in $\%$ \\
\hline Kontrolle & 231 & 78 & 33,8 & 125 & 54,1 & 28 & 12,1 \\
\hline RA & 55 & 20 & 36,4 & 24 & 43,6 & 11 & 20 \\
\hline RARS & 26 & 12 & 46,1 & 10 & 38,5 & 4 & 15,4 \\
\hline CMML & 12 & 6 & 50 & 5 & 41,7 & 1 & 8,3 \\
\hline RAEB & 35 & 15 & 42,8 & 17 & 48,6 & 3 & 8,6 \\
\hline RAEB-T & 18 & 6 & 33,3 & 11 & 61,1 & 1 & 5,6 \\
\hline
\end{tabular}

\subsection{Sekundäre / Therapie-induzierte AML und MDS}

Akute myeloische Leukämien bzw. myelodysplastische Syndrome können als Folgeerkrankung bei Vorbestehen anderer maligner Erkrankungen (z.B. Morbus Hodgkin, NHL) als sogenannte sekundäre Neoplasien auftreten. Andererseits können Strahlenexposition oder Zytostatika als Therapie-induzierte Variante ursächlich sein. Retrospektiv wurden Patienten mit Therapie-induzierter AML bzw. MDS-Syndrom im Hinblick auf die GSTA1-Genotypverteilung untersucht.

Von 40 Erkrankten mit Therapie-induzierter akuter myeloischer Leukämie waren $57,5 \%$ homozygot $h G S T A l * A, 37,5 \%$ konnten als heterozygot identifiziert werden 
und $5,1 \%$ wurden für den homozygoten $h G S T A l * B$-Genotyp erfasst. Untersuchungen aus dem Bereich des Therapie-induzierten MDS-Syndroms ergaben ausgehend von insgesamt 17 Patienten folgende Werte: homozygot $h G S T A{ }^{*} A$ waren 58,8\%, 41,2\% waren heterozygote Genträger und kein Erkrankter nach Chemotherapie konnte dem homozygoten $h G S T A l * B$-Genotyp zugeordnet werden.

Tabelle 10 veranschaulicht diese Ergebnisse.

Tabelle 10: Genotypverteilung für die Therapie-induzierte AML bzw. das Therapie-induzierte MDS-Syndrom.

\begin{tabular}{|c|c|c|c|c|c|c|c|}
\hline & N & $\boldsymbol{h G S T A 1} * \boldsymbol{A}$ & in \% & $\boldsymbol{h G S T A 1}{ }^{* A} \boldsymbol{A} \boldsymbol{B}$ & in \% & $\boldsymbol{h G S T A 1} *_{\boldsymbol{B}}$ & in \% \\
\hline Kontrolle & 231 & 78 & $\mathbf{3 3 , 8}$ & 125 & $\mathbf{5 4 , 1}$ & 28 & $\mathbf{1 2 , 1}$ \\
\hline tAML & 40 & 23 & $\mathbf{5 7 , 5}$ & 15 & $\mathbf{3 7 , 5}$ & 2 & $\mathbf{5 , 1}$ \\
tMDS & 17 & 10 & $\mathbf{5 8 , 8}$ & 7 & $\mathbf{4 1 , 2}$ & 0 & $\mathbf{0 , 0}$ \\
\hline
\end{tabular}




\section{Diskussion}

\subsection{Einführung}

In der vorliegenden Arbeit wurden Blut- und Knochenmarkproben von hämatologischen Patienten auf die von Coles et al. (2001b) beschriebene Sequenzvariation der GSTA1 untersucht. Diese Ergebnisse wurden anschließend im Vergleich zu einem Kontrollkollektiv ausgewertet. Es standen 293 Proben von Patienten mit akuter myeloischer Leukämie zur Verfügung. Davon konnte bei 200 Proben der Genotyp und bei 176 Patienten der Karyotyp bestimmt werden. Von insgesamt 189 MDS-Patienten wurde bei 188 Patienten der Genotyp und bei 177 der Erkrankten der Karyotyp ermittelt. Die nicht verwertbaren Ergebnisse sind auf zum Teil alte Proben mit äußerst geringen DNS-Konzentrationen zurückzuführen (isolierte DNS-Proben von 11/96-12/02).

\subsection{GSTA1-Polymorphismus}

Retrospektiv wurden AML- und MDS-Patienten in Bezug auf den unter 1.2.2 (S. 5) bereits beschriebenen Polymorphismus in der proximalen Promotorregion der GSTA1 untersucht. Die genaue Lokalisation entspricht der Region -721 bis -1 (Coles et al., 2001b). Die $h G S T A 1 * B$-Genvariante ist durch den Basenaustausch $-52 \mathrm{G}>\mathrm{A}$ gekennzeichnet, der für die unterschiedliche Promotoraktivität und damit für die geringere Enzymexpression verantwortlich ist (Morel et al., 2002). Bislang wurden insgesamt 7 SNPs (single nucleotide polymorphisms) für die GSTA1 Promotorregion beschrieben (Coles et al., 2001b; Bredschneider et al., 2002).

Folgende drei Fragestellungen wurden geprüft:

Gibt es einen Unterschied zwischen AML- bzw. MDS-Patienten und gesunden Kontrollpersonen in Bezug auf den GSTA1-Genotyp?

Lässt sich ggf. ein Unterschied in bestimmten FAB-Subgruppen feststellen ?

Gibt es einen Unterschied zwischen Therapie-induzierten AML-/MDS-Patienten und gesunden Kontrollpersonen in Bezug auf den GSTA1-Genotyp?

In der Gruppe der AML-Erkrankten wurden 9,5\% für den homozygoten $h G S T A 1 * B$ Genotyp ermittelt. Für die MDS-Patienten wurden insgesamt 11,7\% für die besagte Genvariante erfasst. Beide Werte waren im Vergleich zum Kontrollwert etwas geringer. Im Kontrollkollektiv lag der Wert für den homozygoten $h G S T A I^{*} B-$ 
Genotyp bei $12,1 \%$, dieser Wert entspricht annähernd den von Coles et al. (2001b) veröffentlichten Kontrollwerten damaliger Kollektive. Anhand der Zytogenetik und der FAB-Klassifikation konnte eine weitere Unterteilung erfolgen (siehe unter: 1.3.2, S. 8 ; 1.3.3, S. 8; 2.2.6, S. 21; 3.3, S. 24; 3.4, S. 25; 3.5, S. 26; 3.6, S. 27).

Aus dem Bereich der AML-Zytogenetik fällt der Zahlenwert des $h G S T A{ }^{*} B-$ Genotyps für den komplexen Karyotyp auf, der 5,4 Prozentpunkte unter dem Kontrollwert lag. Der Wert für den nicht-komplexen Karyotyp wurde mit 12,9\% bestimmt, der geringfügig erhöht ist. Die MDS-Zytogenetik lieferte ähnliche Ergebnisse mit deutlicherer Tendenz. So wurde ein sehr geringer Zahlenwert von 3,3\% für den komplexen Karyotyp ermittelt. Im Gegensatz dazu konnte ein erhöhter Wert von 14,5\% für den nicht-komplexen Karyotyp erfasst werden.

Die Aufschlüsselung der FAB-Klassifikation für die AML-Erkrankten zeigte für den $h G S T A l * B$-Genotyp im M2-Stadium einen erhöhten Wert von 13,4\%. Andererseits wurde für das Stadium M1 ein niedriger Wert von 5\% ermittelt. Andere Zahlenwerte aus dieser Rubrik (z.B. 28,6\% für den AML-Subtyp M0, 22,2\% für den AML-Subtyp M6) sind aufgrund geringer Patientenzahlen $\mathrm{zu}$ vernachlässigen. In der Patientengruppe mit Refraktärer Anämie (MDS-FAB-Klassifikation) wiesen 20\% der Erkrankten den $h G S T A l * B$-Genotyp auf. Auch dieser Wert kann als erhöht gewertet werden, da 55 Patienten dieser Gruppe angehörten. Unter den Patienten mit Refraktärer Anämie mit Ringsideroblasten waren 15,4\% homozygot $h G S T A l * B$, auch hier kann eine erhöhte Tendenz vermerkt werden.

Trotz der angeführten „Ausreißer“ konnten dennoch weder in der AML- noch in der MDS-Gruppe durchgängige Tendenzen bezüglich signifikanter Erniedrigungen bzw. Erhöhungen des $h G S T A l * B$-Genotyps gesichert werden.

Eine aktuelle Arbeit aus Italien untersuchte 160 MDS-Patienten auf verschiedene Polymorphismen und konnte dabei, ebenso wie diese Arbeit, keinen Unterschied in dem Auftreten des $h G S T A l * B$-Genotyps bei MDS-Patienten und gesunden Kontrollen feststellen. Im Gegensatz zu dieser Arbeit lag in den italienischen Kollektiven der Anteil der Personen, die homozygot für den $h G S T A l * B$-Genotyp waren mit 18,2\% (Kontrolle) und 21,8\% (MDS-Patienten) deutlich höher als in den Göttinger Kollektiven (Fabiani et al., 2009). 


\subsection{GSTs und Medikamentenresistenz}

Einige Tumorzellen besitzen die Fähigkeit alkylierende Substanzen zu inaktivieren.

Dadurch scheinen sie mit derart durchgeführter Chemotherapie weniger DNSSchädigung aufzuweisen als Tumorzellen ohne diesen Wirkmechanismus (Dirven et al. 1994). Es wird davon ausgegangen, dass ererbte Variabilitäten in der Metabolisierung therapeutisch wirksamer Agenzien für die unterschiedlichen Erfolge in der Krebstherapie mitverantwortlich sein können (Evans und Relling, 1999) und darüber hinaus eine wichtige Rolle bezüglich des Nebenwirkungspotenzials des Chemotherapeutikums (z.B. Cyclophosphamid) spielen können (Zhong et al., 2006). Cyclophosphamid (CP) findet als Mono- oder Kombinationstherapeutikum in der Krebstherapie seinen Einsatz. Es wird in der Leber aktiviert (Connors et al., 1972), seine zytostatische Potenz erhält die Verbindung nach Metabolisierung in 4Hydroxycyclophosphamid (Dirven et al., 1994). An dieser Aktivierungsreaktion sind hauptsächlich drei menschliche Cytochrom-P450-Enzyme (CYP2B6, CYP2C8, CYP2C9) beteiligt (Chang et al., 1993).

Es wurden Tumorzellen mit erhöhter Resistenz gegenüber alkylierenden Agenzien beobachtet, in denen eine erhöhte intrazelluläre GSH-Konzentration und damit eine größere GST-Aktivität nachweisbar war. Unter diesem Aspekt wurden Untersuchungen durchgeführt, die eine Aussage über die Entgiftungskapazität einiger GSTs in Bezug auf Cyclophosphamid (CP) und dessen Metaboliten treffen sollten. Es wurde unter anderem eine erhöhte Konzentration an GSTA1-1 in den Tumorzellen gemessen, die für eine erhöhte Umsetzung an Agenzien wie auch für die resultierende Resistenz der Zellen gegenüber den Therapeutika verantwortlich zu sein scheint (Dirven et al., 1994).

Beaumont et al. (1998) konnten zeigen, dass in Adenokarzinomzellen (besonders Caco-2-Zellen) des menschlichen Kolons nach Gabe des Anthrazyklins Doxorubicin eine hohe Konzentration an GST- $\alpha$ nachweisbar war. Es wird spekuliert, dass die $\alpha$ GSTs eine entscheidende Rolle bezüglich der bekannten Resistenz der genannten Substanz in der Therapie von Kolon- bzw. Rektummalignomen spielen (Beaumont et al., 1998).

Horton et al. (1999) fanden in Ovarkarzinomzellen, die eine Resistenz gegenüber der alkylierenden Substanz Chlorambucil (CHB) aufwiesen, eine erhöhte Konzentration 
an GSTs der Klasse my im Vergleich zu GSTs der Klassen alpha und pi. Möglicherweise ist diese Überexpression an my-GST mit der genannten Resistenz von Ovarkarzinomzellen gegenüber Chlorambucil assoziiert (Horton et al., 1999).

Maligne Erkrankungen der Ovarien waren auch für andere Forschungsgruppen Untersuchungsgegenstand. So untersuchten Boss et al. (2001) die Konzentrationen an GSTA1-1 sowie an GSTP1-1 in Ovarialzysten verschiedener histopathologischer Klassifikationen. Es fiel eine erhöhte Konzentration an GSTP1-1 in der Zystenflüssigkeit maligner und Borderline-Tumoren im Vergleich zu der benigner Zysten auf. Für die GSTA1-1 konnten allerdings keine signifikanten Konzentrationsunterschiede gesichert werden. Auch wenn erhöhte Konzentrationen an GSTP1 in einigen malignen Ovarialtumoren gefunden wurden (Boss et al., 2001) konnte anhand anderer Untersuchungen kein Zusammenhang des GSTP1Polymorphismus (Codon 105: Isoleucin $\rightarrow$ Valin) mit dem vermehrten Auftreten von epithelialen Ovarialkarzinomen hergestellt werden (Coughlin und Hall, 2002).

2001 veröffentlichte Ergebnisse von Paumi et al. stellten einen Zusammenhang einer vermehrten Expression an GSTA1-1 sowie einer Koexpression an MRP1 (multidrug resistance-associated protein 1) und der Resistenz gegenüber Chlorambucil (CHB) her. Im Zellmodell konnte nachgewiesen werden, dass eine Expression des Glutathion-Konjugat-(efflux)-Transporters MRP1 zusammen mit einer hohen Expressionsrate an GSTA1-1 für die Resistenz dieser Zellen gegenüber CHB verantwortlich ist. Der gleiche Effekt konnte allerdings nicht für das strukturell ähnliche Alkylans Melphalan (MLP) gezeigt werden, obwohl es von der GSTA1-1 konjugiert und anschließend mittels MRP1-Transporter aus den Zellen transportiert wird (Paumi et al., 2001). Untersuchungen von Smitherman et al. (2004) zeigten anhand eines anderen Zellmodells, dass auch MRP2 (multidrug resistance-associated protein 2) die GSTA1-1-vermittelte Resistenz gegenüber CHB potenziert.

Es konnte also anhand mehrerer Untersuchungen veranschaulicht werden, dass hohe Konzentrationen an GSTs mit einem hohen Umsatz an Therapeutikum einhergehen. Auch der entgegengesetzte Effekt konnte veranschaulicht werden. JaitovitchGroisman et al. (2000) führten Experimente mit HepG2-Zellen durch, die mit dem Hepatitis-B-Virus transfiziert wurden. In diesen Zellen war eine erniedrigte Konzentration an GST alpha nachweisbar, die mit einer geringeren GST-Peroxidase- 
Aktivität verbunden war. Dadurch konnte eine Hypersensitivität der HepG2-Zellen bezüglich einiger Alkylanzien wie Melphalan, BCNU (1,3-bis(2-chlorethyl)-1Nitrosoharnstoff) und Cisplatin dargestellt werden (Jaitovitch-Groisman et al., 2000).

\subsection{GSTA1 und VOD (Veno-occlusive disease)}

Veno-occlusive disease oder auch hepatische Venenverschlusskrankheit zählt zu den häufigsten Komplikationen nach allogener Knochenmarks- bzw. Stammzelltransplantation. Diese Transplantationsarten gehören zu etablierten Therapieverfahren maligner hämatologischer Erkrankungen wie AML, CML, MDS. VOD tritt häufig nach Hochdosistherapie mit der zur „Konditionierung“ verwendeten antineoplastischen Substanz Busulfan auf. Da Busulfan unter anderem dem Metabolismus der GSTA1-1 unterliegt (Czerwinski et al., 1996) wurden Untersuchungen durchgeführt, um einen möglichen Zusammenhang der VOD mit Expressionsveränderungen der GSTA1 herzustellen. Bredschneider et al. (2002) identifizierten eine Reihe von SNPs der GSTA1, dennoch konnten sie keine Korrelation zur GSTA1-Expression und VOD herstellen. Ritter et al. (2002) hingegen zeigten im Zellmodell mit ECV 304-Zellen, dass eine Überexpression an GSTA1-1 nicht nur eine vermehrte Konjugation an Busulfan nach sich zieht, sondern auch für eine Mehrproduktion an Gewebsfaktor verantwortlich zu sein scheint. Damit wird spekuliert, dass die GSTA1-1 eine zentrale Rolle in der Entstehung von Koagulationsstörungen wie VOD bei Patienten mit Busulfantherapie spielt (Ritter et al., 2002).

\subsection{Kolorektale Malignome, Mammakarzinome und GSTs}

Polyzyklische aromatische Hydrokarbone (PAHs), weitverbreitete Verbindungen in Nahrungs- und Genussmitteln (Tabak), werden zum Teil mithilfe von GSTs (GSTM1, GSTT1) detoxifiziert (Hirvonen, 1995). Dieser Stoffgruppe zugehörige Umweltschadstoffe wie Dibenzpyrendiolepoxid werden vorrangig durch die $\alpha$-GSTs, im Besondern von der GSTA1-1 umgesetzt (Dreij et al., 2002). PAHs wurden mit der Entstehung kolorektaler Malignome in Verbindung gebracht (Cotton et al., 2000). 
Das Risiko für die Entwicklung kolorektaler Karzinome ist erhöht mit Vorliegen des bereits beschriebenen $h G S T A l{ }^{*} B$-Genotyps (siehe 1.2.2, S. 5). Möglicherweise als Folge unzureichender hepatischer Detoxifikation von $N$-acetoxy-PhIP ( $\mathrm{PhIP}=2-$ amino-1-methyl-6-phenylimidazo[4,5-b]pyridin), einem in gebratenen Fleisch befindlichen heterozyklischen Amin, könnte der weniger aktive $h G S T A l * B$-Genotyp einen Risikofaktor darstellen (Coles et al., 2001a; Sweeney et al., 2002). Da im Kolon und Magen eine weitaus geringere Expressionsrate an GSTA1 und GSTA2 im Vergleich zum Duodenum oder auch Jejunum ermittelt werden konnte, besitzen die erstgenannten Organe eine geringere GST-abhängige Detoxifikation chemischer Karzinogene. Sie könnten möglicherweise ein höheres Risiko gegenüber genotoxischen Effekten haben, die im Speziellen auf GSTA1-/A2-spezifische Substrate zurückzuführen sind (Coles et al., 2002).

Der $h G S T A l * B$-Genotyp, welcher mit einer geringeren hepatischen Enzymexpressionsrate einhergeht (Coles et al., 2001b), wurde auch im Hinblick auf die Überlebensrate nach Mammakarzinom untersucht. In der retrospektiv durchgeführten Studie, bei der Brustkrebspatienten eine Kombinationschemotherapie mit Cyclophosphamid (CP) (entweder CP+Methotrexat+5-Fluoruracil oder $\mathrm{CP}+$ Adriamycin(+5-Fluoruracil)) erhielten, konnte der homozygote $h G S T A l * B$ Polymorphismus mit einer erhöhten 5-Jahresüberlebensrate in Zusammenhang gebracht werden (Sweeney et al., 2003). Ein ähnlich erhöhtes Überleben war in einer Studie bei Mammakarzinompatienten für die GSTP1-105-Val-Genvariante aufgefallen (Sweeney et al., 2000). GSTA1 wie auch GSTP1 nutzen möglicherweise den gleichen Mechanismus in der Detoxifikation von Cyclophosphamid (CP). Andere Ergebnisse bezüglich des GSTP1 Ile(105)Val-Polymorphismus zeigten ein erhöhtes Überleben bei Kolonkarzinompatienten, die 5- Fluoruracil/Oxaliplatin als Chemotherapeutikum erhielten (Stoehlmacher et al., 2002).

Der mit diesen Polymorphismen verbundene Aktivitätsverlust der jeweiligen Enzyme scheint für eine höhere Wirksamkeit an Therapeutikum verantwortlich zu sein (Sweeney et al., 2002). Daher ergab sich in der von Sweeney et al. durchgeführten Untersuchung eine höhere 5-Jahresüberlebensrate, auch wenn für einen noch längeren Zeitraum (> 5-Jahresüberleben) dafür kein Beweis erbracht werden konnte. 
Der Einfluss des GSTA1-Genotyps auf die Pharmakokinetik von Thiotepa und Tepa wurde bei onkologischen Patienten untersucht, die überwiegend unter Mammakarzinom litten. Für die nichtinduzierbare Clearance von Thiotepa wurde eine Reduzierung bei Patienten festgestellt, die homozygote Träger des $h G S T A{ }^{*} B$ Genotyps waren. Daraus wurde ein 17\%iger Anstieg der Exposition gegen Thiotepa errechnet (Ekhart et al., 2008a). In dem gleichen Kollektiv untersuchten die Autoren vergeblich einen möglichen Einfluss des GSTA1-Genotyps auf die Pharmakokinetik von Cyclophosphamid (Ekhart et al., 2008b).

\subsection{Sekundäre und Therapie-induzierte Malignome}

In dieser Arbeit sollte ebenfalls der Fokus auf die mögliche Relevanz des GSTA1Gendefekts auf die Pathogenese Therapie-induzierter, sekundärer hämatologischer Malignome gerichtet werden.

Unerwünschte Langzeitkomplikationen etablierter Radio- und/bzw. Chemotherapien sind häufig mit dem Auftreten einer sekundären AML bzw. einem sekundären MDSSyndrom verbunden. Der Grund dafür ist die leukämogene Aktivität vieler genutzter Agenzien in der Therapie primärer Malignome (Pagano et al., 2001).

Es existieren hauptsächlich zwei unterschiedliche sekundäre Leukämieformen: Alkylanzien-induzierte Leukämien mit Chromosom -5- und -7-Anomalien sowie Leukämien mit MLL-Gen-Translokation und anderen Veränderungen nach Topoisomerase-II-Inhibitor-Therapie (Felix 1998).

Tabelle 11 zeigt die Charakteristika sekundärer Leukämien nach Behandlung mit dem jeweiligen Therapeutikum. 
Tabelle 11: Charakteristika sekundärer Leukämien nach Gabe unterschiedlicher Therapeutika.

\begin{tabular}{c|cc}
\hline Charakteristika & Alkylanz & $\begin{array}{c}\text { Topoisomerase-II-Hemmer } \\
\text { (Epipodophyllotoxin) }\end{array}$ \\
\hline Intervall nach Therapie (Jahre) & $5-7$ & $2-3$ \\
FAB-Klassifikation & M1/M2 & M4/M5 \\
Übergang aus MDS & oft & selten \\
Chromosomenaberrationen & $(-5)$ oder (-7) & Translokationen der Banden \\
& del (5q) & 11q23 und 21q22 \\
\hline
\end{tabular}

(Kollmannsberger et al., 1998, S. 208)

Auch das sekundäre MDS-Syndrom zeigt charakteristische zytogenetische Veränderungen. Vermehrt fanden sich: $-7 ; 5 q-;-5 ; 7 q-$ und $t(1 ; 7)$. Dem gegenüber stehen zytogenetische Veränderungen, die gehäuft bei de-novo-MDS-Patienten auftraten: +8 und $-\mathrm{y}$ (Johansson et al., 1991). Prädisponierend für Therapiebegleitende sekundäre maligne Erkrankungen kann die unterschiedliche Medikamenteninteraktion mit dem jeweiligen Organismus sein. Polymorphismen Fremdstoff-metabolisierender Enzyme (z.B. NAD(P)H:Chinonoxidoreduktase) wurden mit einem erhöhtem Risiko an sekundärer Leukämie/MDS zu erkranken assoziiert (Larson et al., 1999). Aber auch eine unzureichende GST-Aktivität kann mit dem Auftreten von t-AML bzw. t-MDS assoziiert sein, da viele zytotoxische Verbindungen wie Melphalan, Mitomycin C, Cisplatin und Cyclophosphamid zu inaktiven Metaboliten mittels GSTs umgesetzt werden (Hoban et al., 1992; Chen G und Waxmann, 1994; Golub, 1999). So ist das Risiko für das Auftreten einer Therapie-induzierten AML nach erhaltener zytotoxischer Chemotherapie gesteigert bei Vorliegen von wenigstens einem Val-Allel des GSTP1-105-Codons (Allen et al., 2001). Dieser Polymorphismus, der für eine geringere Enzymaktivität steht, kann andererseits von Vorteil sein. Es wurde nicht nur für Brustkrebs- und Darmkrebspatienten eine höhere Überlebensrate nach Chemotherapie beobachtet (Sweeney et al., 2000; Stoehlmacher et al., 2002), sondern diese Genvariante scheint auch mit einer geringeren Rezidivrate bei Prä-B-ALL im Kindesalter assoziiert zu sein (Stanulla et al., 2000). 
Davies et al. (2001) konnten zeigen, dass mit Auftreten des GSTT1-«null» Genotyps, der in Europa zwischen 10\% und $30 \%$ in der Bevölkerung auftritt (Schulz et al., 2002), eine geringere Überlebens- bzw. eine höhere Mortalitätsrate von AMLPatienten nach intensiver Chemotherapie verbunden ist.

Die in dieser Arbeit untersuchten Patienten mit sekundärer AML wiesen hauptsächlich mit $59 \%$ den heterozygoten $h G S T A l * A / B$-Genotyp auf. Lediglich $5,1 \%$ konnten als homozygot $h G S T A l * B$ identifiziert werden. Aus dem Bereich der Therapie-induzierten AML konnten nur 5\% mit der $h G S T A 1 * B$-Genvariante erfasst werden. Patienten mit Therapie-induziertem Myelodysplastischen Syndrom wiesen nicht den genannten Genotyp auf.

Folglich konnte aus der Rubrik der sekundären, Therapie-induzierten Malignome eine erniedrigte Anzahl an homozygoten $h G S T A l^{*} B$-Genträgern ermittelt werden. Dieses Ergebnis wiederlegt die vorherige Annahme, da man eher von einer Erhöhung des $h G S T A l * B$-Genotyps ausgegangen war. So scheint nach den durchgeführten Untersuchungen die $h G S T A 1 * B$-Genvariante nicht aufgrund möglicher geringerer Detoxifikationseigenschaften mit dem Auftreten sekundärer, Therapie-induzierter hämatologischer Malignome, im Speziellen der AML und dem MDS-Syndrom, assoziiert zu sein.

\subsection{Nicht-maligne Erkrankungen und GSTA1}

In japanischen Kollektiven wurde der Zusammenhang zwischen GST-Genotypen und dem Vorliegen von Bluthochdruck untersucht. Als hypertensiv wurden Patienten mit einem systolischen Blutdruck von größer oder gleich $140 \mathrm{~mm} \mathrm{Hg}$ und einem diastolischen Blutdruck von größer oder gleich $90 \mathrm{~mm} \mathrm{Hg}$ eingestuft. Für die Auswertung wurden die Träger von einem bzw. zwei $h G S T A l * B$-Allelen zusammengefasst und mit den homozygoten Trägern des hGSTAl*A-Allels verglichen. Es zeigte sich, dass 19,2 \% der normotensiven Kontrollen mindestens ein $h G S T A l^{*} B$-Allel trugen, während dies unter den hypertensiven Studienteilnehmern 28,5\% waren. Die Autoren spekulieren darüber, ob der oxidative Stress in der Niere, der $\mathrm{zu}$ einer Bildung von NO führen kann, eventuell von dem GSTA1Polymorphismus beeinflusst werden kann und dadurch ggf. die Manifestation von Bluthochdruck mit erklärt werden könnte (Oniki et al., 2008). 


\section{Zusammenfassung}

Seit längerem sind Fremdstoff-metabolisierende Enzyme (FME) Untersuchungsgegenstand verschiedener Forschungsgruppen. Es wurde eine Reihe von Polymorphismen der FME beschrieben, die mit einer erhöhten Suszeptibilität bezüglich der Entstehung verschiedener Malignome assoziiert werden konnten. Zusätzlich scheinen einige dieser Polymorphismen mit einem erhöhten Risiko in Bezug auf die Entwicklung sekundärer maligner Erkrankungen wie Leukämien oder Myelodysplastisches Syndrom verbunden zu sein. Da die Familie der Glutathion-STransferasen innerhalb des Phase-II-Stoffwechsels eine zentrale Rolle in der Entgiftung spielen, waren und sind auch ihre Polymorphismen äußerst forschungsrelevant.

Der $h G S T A 1 * B$-Polymorphismus in der proximalen Promotorregion der GSTA1 ist für die unterschiedliche Promotoraktivität und damit für eine geringere Enzymexpression verantwortlich.

Wir untersuchten in dieser Arbeit mittels PCR und Restriktionsenzymverdau, ob die $h G S T A l * B$-Genvariante gehäuft bei Patienten mit AML oder MDS als primäre oder sekundäre, Therapie-induzierte Krankheitsform vorkommt. Bei den AML-Patienten (primäre AML) ergab sich für den $h G S T A l * B$-Genotyp ein Wert von 9,5\% und für die MDS-Erkrankten (primäres MDS) ein Wert von 11,7\%. Beide Werte unterschieden sich nicht signifikant von den 12,1\%, die für das Kontrollkollektiv gemessen wurden. Aus dem Bereich der Therapie-induzierten AML konnten nur 5\% mit der $h G S T A l * B$-Genvariante ermittelt werden. Kein Patient mit Therapieinduziertem MDS konnte als $h G S T A l * B$-Genträger erfasst werden. Folglich ergab sich entgegen anfänglichen Erwartungen keine signifikante Erhöhung der genannten Genvariante bezüglich Therapie-induzierter AML-/ MDS-Erkrankter.

Die von uns durchgeführten Untersuchungen konnten keinen Zusammenhang des $h G S T A{ }^{*} B$-Polymorphismus, der möglicherweise über geringere Detoxifikationseigenschaften verfügt, mit dem Auftreten einer primären oder Therapie-induzierten AML/MDS herstellen. 


\section{Abkürzungsverzeichnis}

ALL

AML

$\mathrm{BCNU}$

$\mathrm{bp}$

C

CDNB

cDNS

$\mathrm{CHB}$

CMML

CML

$\mathrm{CP}$

CYP

dATP

$\mathrm{dCTP}$

del5q

dGTP

DNS

dNTP

DTT

dTTP

E

Ear I

EDTA

EST-Datenbank

FAB

FME

g

GSH

GST

$\mathrm{HCl}$

hGST akute lymphatische Leukämie

akute myeloische Leukämie

1,3-bis(2-chlorethyl)-1-Nitrosoharnstoff

Basenpaare

Konzentration

1-Chlor-2,4-dinitrobenzol

copy-DNS, DNS-Kopie der RNA

Chlorambucil

chronische myelomonozytäre Leukämie

chronische myeloische Leukämie

Cyclophosphamid

Cytochrom-P450

Desoxyadenosintriphosphat

Desoxycytidintriphosphat

Deletion am langen Arm von Chromosom 5

Desoxyguanosintriphosphat

Desoxyribonukleinsäure

Desoxynukleotidtriphosphat

1,4-Dithiothreitol

Desoxythymidintriphosphat

Extinktion

Restriktionsenzym aus Enterobacter aerogenes

Ethylendiamintetraacetat

Expressed-Sequence-Tag-Datenbank

French-American-British-Group

Fremdstoff-metabolisierende Enzyme

Gramm

Glutathion

Glutathion-S-Transferase

Salzsäure

human Glutathion- $S$-Transferase 


\begin{tabular}{|c|c|}
\hline \multirow[t]{2}{*}{$h G S T A l * A$} & homozygote Genvariante A der human \\
\hline & Glutathion- $S$-Transferase A1 \\
\hline \multirow[t]{2}{*}{$h G S T A l * A / B$} & heterozygote Genvariante A/B der human \\
\hline & Glutathion-S-Transferase A1 \\
\hline \multirow[t]{2}{*}{$h G S T A l * B$} & homozygote Genvariante B der human \\
\hline & Glutathion- $S$-Tarnsferase A1 \\
\hline $\mathrm{H}_{2} \mathrm{O}_{2}$ & Wasserstoffperoxid \\
\hline $\mathrm{Kb}$ & Kilobasen \\
\hline $\mathrm{KHCO}_{3}$ & Kaliumhydrogenkarbonat \\
\hline M & Mol \\
\hline MDS & Myelodysplastisches Syndrom \\
\hline $\mathrm{mg}$ & Milligramm \\
\hline $\mathrm{MgCl}_{2}$ & Magnesiumchlorid \\
\hline $\min$ & Minute \\
\hline $\mathrm{ml}$ & Milliliter \\
\hline MLL & myeloische lymphatische Leukämie \\
\hline MLP & Melphalan \\
\hline $\mathrm{mM}$ & Millimol \\
\hline MRP & Multidrug resistance-associated protein \\
\hline M0 & undifferenzierte akute Leukämie \\
\hline M1 & AML ohne Ausreifung \\
\hline $\mathrm{M} 2$ & AML mit Ausreifung \\
\hline M3 & Promyelozytenleukämie \\
\hline M4 & akute myelomonozytäre Leukämie \\
\hline M5 & akute monozytäre Leukämie \\
\hline M6 & akute Erythroleukämie \\
\hline M7 & akute megakaryozytäre Leukämie \\
\hline$\mu 1$ & Mikroliter \\
\hline $\mathrm{NaCl}$ & Natriumchlorid \\
\hline $\mathrm{NAD}(\mathrm{P}) \mathrm{H}$ & Chinonoxidoreduktase \\
\hline NE-Buffer 1 & New-England Buffer 1 \\
\hline ng & Nanogramm \\
\hline
\end{tabular}


$\mathrm{NH}_{4} \mathrm{Cl}$

NHL

NK

nm

OD

$\mathrm{PAH}$

PCR

$\mathrm{PhIP}$

pmol

p53

RA

RARB

RARB/T

RARS

s-AML

SDS

SNP

t-AML

Taq-DNS-Polymerase

Taq-Puffer

TBE-Puffer

TE-Puffer

U

UV

V

Val

VE-Wasser

VOD

Vol
Ammoniumchlorid

Non-Hodgkin-Lymphom

nicht-komplex

Nanometer

Optical density

Polyzyklische aromatische Hydrokarbone

Polymerase-Ketten-Reaktion

2-amino-1-methyl-6-phenylimidazo[4,5-

b]pyridin

Pikomol

DNS-Reperaturgen p53

Refraktäre Anämie

Refraktäre Anämie mit Blastenüberschuss

Refraktäre Anämie mit Blastenüberschuss

in Transformation

Refraktäre Anämie mit Ringsideroblasten

sekundäre akute myeloische Leukämie

Natriumdodecylsulfat

Single nucleotide polymorphisms

Therapie-assoziierte akute myeloische Leukämie

DNS-abhängige DNS-Polymerase aus

Thermophilus aquaticus

Puffer der DNS-Polymerase

Trisboratethylendiamintetraacetat

Trisethylendiamintetraacetat

Unit

Ultraviolett

Verdünnungsfaktor

Valin

vollentionisiertes Wasser

Veno-occlusive diseases

Volumen 


\section{Literaturverzeichnis}

Allen JM, Wild CP, Rollinson S, Willett EV, Moorman AV, Dovey GJ, Roddam PL, Roman E, Cartwright RA, Morgan GJ (2001): Polymorphism in glutathione Stransferase P1 is associated with susceptibility to chemotherapy-induced leukemia. Proc Natl Acad Sci USA $\underline{98}, 11592-11597$

Atoyebi W, Kusec R, Fidler C, Peto TE, Boultwood J, Wainscoat JS (1997): Glutathion S-transferase gene deletions in myelodysplasia. Lancet $\underline{349}$, 1450-1451

Basu T, Gale RE, Langabeer S, Linch DC (1997): Glutathione S-transferase theta 1 (GSTT1) gene defect in myelodysplasia and acute myeloid leukemia. Lancet $\underline{349}$, 1450

Beaumont PO, Moore MJ, Ahmad K, Payne MM, Lee C, Riddick DS (1998): Role of glutathione S-transferases in the resistance of human colon cancer cell lines to doxorubicin. Cancer Res $\underline{58}$, 947-955

Ben-Yehuda D, Krichevsky S, Caspi O, Rund D, Polliack A, Abeliovich D, Zelig O, Yahalom V, Paltiel O, Or R, Peretz T, Ben-Neriah S, Yehuda O, Rachmilewitz EA (1996): Microsatellite instability and p53 mutations in therapy-related leukemia suggest mutator phenotype. Blood $\underline{88}$, 4296-4303

Board P (2002): Ligandin revisited: resolution of the alpha class glutathione transferase gene family. Pharmacogenetics $\underline{12}$, 275-276

Board PG, Coggan M, Chelvanayagam G, Easteal S, Jermiin LS, Schulte GK, Danley DE, Hoth LR, Griffor MC, Kamath AV, Rosner MH, Chrunyk BA, Perregaux DE, Gabel CA, Geoghegan KF, Pandit J (2000): Identification, characterization, and crystal structur of the Omega class glutathione transferases. J Biol Chem 275, 24798-24806 
Boss EA, Peters WH, Roelofs HM, Boonstra H, Steegers EA, Massuger LF (2001): Glutathione S-transferases P1-1 and A1-1 in ovarian cyst fluids. Eur J Gynaecol Oncol $\underline{22}, 427-432$

Bredschneider M, Klein K, Mürdter TE, Marx C, Eichelbaum M, Nüssler AK, Neuhaus P, Zanger UM, Schwab M (2002): Genetic polymorphisms of glutathione S-transferase A1, the major glutathione S-transferase in human liver: consequences for enzyme expression and busulfan conjugation. Clin Pharmacol Ther $\underline{71}$, 479-487

Carmichael J, Forrester LM, Lewis AD, Hayes JD, Hayes PC, Wolf CR (1988): Glutathione S-transferase isoenzymes and glutathione peroxidase activity in normal and tumour sampler from human lung. Carcinogenesis $\underline{9}, 1617-1621$

Chang TK, Weber GF, Crespi CL, Waxman DJ (1993): Differential activation of cyclophosphamide and isophamide by cytochromes $\mathrm{P} 4502 \mathrm{~B}$ and $3 \mathrm{~A}$ in human liver microsomes. Cancer Res 53, 5629-5637

Chen G, Waxman DJ (1994): Role of cellular glutathione and glutathione Stransferase in the expression of alkylating agent cytotoxicity in human breast cancer cells. Biochem Pharmacol 47, 1079-1087

Chen H, Sandler DP, Taylor JA, Shore DL, Liu E, Bloomfield CD, Bell DA (1996): Increased risk for myelodysplastic syndromes in individuals with glutathione transferase theta 1 (GSTT1) gene defect. Lancet 347, 295-297

Ciccone G, Mirabelli D, Levis A, Gavarotti P, Rege-Cambrin G, Davico L, Vineis P (1993): Myeloid leukemias and myelodysplstic syndromes: chemical exposure, histologic subtype and cytogenetics in a case-control study. Cancer Genet Cytogenet $\underline{15}, 135-139$

Coles B, Ketterer B (1990): The role of glutathione and glutathione transferases in chemical carcinogenesis. Crit Rev Biochem Mol Biol 25, 47-70 
Coles BF, Nowell SA, MacLeod SL, Sweeney C, Lang NP, Kadlubar FF (2001a): The role of human glutathione S-transferases (hGSTs) in the detoxification of the food- derived carcinogen metabolite $\mathrm{N}$-acetoxy-PhIP, and the effect of a polymorphism in hGSTA1 on colorectal cancer risk. Mutat Res $\underline{482}, 3-10$

Coles BF, Morel F, Rauch C, Huber WW, Yang M, Teitel CH, Green B, Lang NP, Kadlubar FF (2001b): Effect of polymorphism in the human glutathione Stransferase A1 promoter on hepatic GSTA1 and GSTA2 expression. Pharmacogenetics $\underline{11}, 663-669$

Coles BF, Chen G, Kadlubar FF, Radominska-Pandya A (2002): Interindividual variation and organ-specific patterns of glutathione S-transferase alpha, mu and pi expression in gastrointestinal tract mucosa of normal individuals. Arch Biochem Biophys $\underline{15}$, 270-276

Commandeur JNM, Stijntjes GJ, Vermeulen NPE (1995): Enzymes and transport systems involved in the formation and disposition of glutathione S-conjugates. Role in bioactivation and detoxication mechanisms of xenobiotics. Pharmacol Rev $\underline{47}$, 271-330

Connors TA, Foster AB, Gilsenan AM, Jarman M, Tisdale MJ (1972): Observations on the metabolism of cyclophosphamide. Biochem Pharmacol 21, 1373-1376

Cotton SC, Sharp L, Little J, Brockton N (2000): Glutathione S-transferase polymorphisms and colorectal cancer. A HuGE review. Am J Epidemiol 151, 7-32

Coughlin SS, Hall IJ (2002): Glutathione S-transferase polymorphisms and risk of ovarian cancer. A HuGE review. Genet Med 4, 250-257 
Curtis RE, Boice JD, Stovall M, Bernstein L, Greenberg RS, Flannery JT, Schwartz AG, Weyer P, Moloney WC, Hoover RN (1992): Risk of leukemia after chemotherapy and radiation treatment for breast cancer. N Engl J Med 25, 17451751

Czerwinski M, Gibbs JP, Slattery JT (1996): Busulfan conjugation by glutathione Stransferases alpha, mu, and pi. Drug Metab Dispos 24, 1015-1019

Daly AK, Thomas DJ, Cooper J, Pearson WR, Neal DE, Idle JR (1993): Homozygous deletion of gene for glutathione S-transferase M1 in bladder cancer. Br Med J $\underline{307}, 481-482$

Davies SM, Robison LL, Buckley JD, Tjoa T, Woods WG, Radloff GA, Ross JA, Perentesis JP (2001): Glutathione S-transferase polymorphisms and outcome of chemotherapy in childhood acute myeloid leukemia. J Clin Oncol 19, 1279-1287

Dekant W, Vamvakas S, Koob M, Köchling A, Kanhai W, Müller D, Henschler D (1990): A mechanism of haloalkene-induced renal carcinogenesis. Environ Health Perspect $\underline{88}, 107-110$

Deschler B, Lübbert M (2006): Acute myeloid leukemia: epidemiology and etiology. Cancer 107, 2099-2107

Dierlamm J, Schilling G, Michaux L, Hinz K, Penas EM, Seeger D, Hagemeijer A, Hossfeld DK (2003): Deletion of chromosome 15 represents a rare but recurrent chromosomal abnormality in myelocytic malignancies. Cancer Genet Cytogenet $\underline{144}$, $1-5$

Dirven HA, van Ommen B, van Bladeren PJ (1994): Involvement of human glutathione S-transferase isoenzymes in the conjugation of cyclophosphamide metabolites with glutathione. Cancer Res $\underline{54}$, 6215-6220 
Dirven HA, van Ommen B, van Bladeren PJ (1996): Glutathione conjugation of alkylating cytostatic drugs with a nitrogen mustard group and the role of glutathione S-trasferases. Chem Res Toxicol $\underline{9}, 351-360$

Dreij K, Sundberg K, Johansson AS, Nordling E, Seidel A, Persson B, Mannervik B, Jernström B (2002): Catalytic activities of human alpha class glutathione transferases toward carcinogenic dibenzo[a,1]pyrene diol epoxides. Chem Res Toxicol $\underline{15}, 825-$ 831

Eickelmann P, Ebert T, Warskulat U, Schulz WA, Sies H (1994): Expression of NAD(P)H:quinone oxidoreductase and glutathione S-transferse $\alpha$ and $\pi$ in human renal cell carcinoma and in kidney cancer-derived cell lines. Carcinogenesis $\underline{15}, 219$ 225

Ekhart C, Doodeman VD, Rodenhuis S, Smits PHM, Beijnen JH, Huitema ADR (2008a): Polymorphisms of drug-metabolizing enzymes (GST, CYP2B6 and CYP3A) affect the pharmacokinetics of thiotepa and tepa. Br J Clin Pharmacol $\underline{67}$, $50-60$

Ekhart C, Doodeman VD, Rodenhuis S, Smits PHM, Beijnen JH, Huitema ADR (2008b): Influence of polymorphisms of drug metabolizing enzymes (CYP2B6, CYP2C9, CYP2C19, CYP3A4, CYP3A5, GSTA1, GSTP1, ALDH1A1 and ALDH3A1) on the pharmacokinetics of cyclophosphamide and 4hydroxycyclophosphamide. Pharmacogenet Genomics $\underline{18}$, 515-523

Evans WE, Relling MV (1999): Pharmacogenomics: translating functional genomics into rational therapeutics. Science $\underline{286}, 487-491$

Fabiani E, D`Alo F, Scardocci A, Greco M, Di Ruscio A, Criscuolo M, Fianchi L, Pagano L, Hohaus S, Leone G, Voso MT (2009): Polymorphisms of detoxification and DNA repair enzymes in myelodysplastic syndromes. Leuk Res $\underline{33}$, 1068-1071 
Felix CA (1998): Secondary leukemias induced by topoisomerase-targeted drugs. Biochem Biophys Acta $\underline{1400}$, 233-255

Felix CA, Walker AH, Lange BJ, Williams TM, Winick NJ, Cheung NKV, Lovett BD, Nowell PC, Blair IA, Rebbeck TR (1998): Association of CYP3A4 genotype with treatment-related leukemia. Proc Natl Acad Sci 95, 13176-13181

Forestier E, Izraeli S, Beverloo B, Haas O, Pession A, Michalova K, Stark B, Harrison CJ, Teigler-Schlegel A, Johansson B (2008): Cytogenetic features of acute lymphoblastic and myeloid leukemias in pediatric patients with Down syndrome: an iBFM-SG study. Blood 111, 1575-1583

Garnier R, Rambourg-Schepens MO, Müller A, Hallier E (1996): Glutathione transferase activity and formation of macromolecular adducts in two cases of acute methyl bromide poisoning. Occup Environ Med 53, 211-215

Golub TR: The genetics of AML: an Update. American Society of Hematology $1999,102-119$

Haase D, Binder C, Bünger J, Fonatsch C, Streubel B, Schnittger S, Griesinger F, Westphal G, Schoch C, Knopp A, Berkovicz D, Krieger O, Wörmann B, Hilgers R, Hallier E, Schulz T (2002): Increased risk for therapy-associated hematologic malignancies in patients with carcinoma of the breast and combined homozygous gene deletions of glutathione transferases M1 and T1. Leuk Res $\underline{26}, 249-254$

Hallier E (2002): Genetische Disposition bei fremdstoffbedingten Erkrankungen. Dtsch Ärztebl 99, 112-114

Hallier E, Deutschmann S, Reichel C, Bolt HM, Peter H (1990): A comparative investigation of the metabolism of methyl bromide and methyl iodide in human erythrocytes. Int Arch Occup Environ Health $\underline{62}$, 221-225 
Harries LW, Stubbins MJ, Forman D, Howard GC, Wolf CR (1997): Identification of genetic polymorphisms at the glutathione S-transferase Pi locus and association with susceptibility to bladder, testicular and prostate cancer. Carcinogenesis $\underline{18}, 641$ 644

Hayes JD, Pulford DJ (1995): The glutatione S-transferase supergene family: regulation of GST and the contribution of the isoenzymes to cancer chemoprotection and drug resistance. Crit Rev Biochem Mol Biol 30, 445-600

Hayes JD, Flanagan JU, Jowsey IR (2005): Glutathione Transferases. Annu Rev Pharmacol Toxicol $\underline{45}, 51-88$

Henderson CJ, McLaren AW, Moffat GJ, Bacon EJ, Wolf CR (1998): Pi-class glutathione S-transferase: regulation and function. Chem Biol Interact 111-112, 6982

Herold G: Innere Medizin, Eigenverlag Gerd Herold, Köln 2008

Hirvonen A (1995): Genetic factors in individual responses to environmental exposures. J Occup Environ Med 37, 37-43

Hoban PR, Robson CN, Davies SM, Hall AG, Cattan AR, Hickson ID, Harris AL (1992): Reduced topoisomerase II and elevated alpha class glutathione S-transferase expression in a multidrug resistant $\mathrm{CHO}$ cell line highly cross-resistant to mitomycin C. Biochem Pharmacol $\underline{43}$, 685-693

Horton JK, Roy G, Piper JT, Van Houten B, Awasthi YC, Mitra S, Alaoui-Jamali MA, Boldogh I, Singhal SS (1999): Characterization of a chlorambucil-resistant human ovarian carcinoma cell line overexpressing glutathione S-transferase mu. Biochem Pharmacol 58, 693-702 
Howie AF, Forrester LM, Glancey MJ, Schlager JJ, Powis G, Beckett GJ, Hayes JD, Wolf CR (1990): Glutathione S-transferase and glutathione peroxidase expression in normal and tumour human tissues. Carcinogenesis $\underline{11}, 451-458$

Jaitovitch-Groisman I, Fotouhi-Ardakani N, Schecter RL, Woo A, Alaoui-Jamali MA, Batist G (2000): Modulation of glutathione S-transferase alpha by hepatitis B virus and the chemopreventive drug oltipraz. J Biol Chem 275, 33395-33403

Johansson B, Mertens F, Heim S, Kristoffersson U, Mitelman F (1991): Cytogenetics of secondary myelodysplasia (sMDS) and acute nonlymphocytic leukemia (sANLL). Eur J Haematol 47, 17-27

Karp JE, Smith MA (1997): The molecular pathogenesis of treatment-induced (secondary) leukemias: foundations for treatment and prevention. Semin Oncol 24, 103-113

Klöne A, Weidner U, Hussnätter R, Harris J, Meyer D, Peter S, Ketterer B, Sies H (1990): Decreased expression of the glutathione S-transferases alpha and pi genes in human renal cell carcinoma. Carcinogenesis $\underline{11}, 2179-2183$

Kollmannsberger C, Hartman JT, Kanz L, Bokemeyer C (1998): Risk of secondary myeloid leukemia and myelodysplastic syndrome following standard-dose chemotherapy or high-dose chemotherapy with stem cell support in patients with potentially curable malignancies. J Cancer Res Clin Oncol 124, 207-214

Larson RA, Wang Y, Banerjee M, Wiemels J, Hartford C, Le Beau MM, Smith MT (1999): Prevalence of the inactivating ${ }^{609} \mathrm{C} \mathrm{T}$ polymorphism in the $\mathrm{NAD}(\mathrm{P}) \mathrm{H}$ :quinone oxidoreductase (NQO1) gene in patients with primary and therapy-related myeloid leukemia. Blood 94, 803-807

Leone G, Voso MT, Sica S, Morosetti R, Pagano L (2001): Therapy related leukemias: Susceptibility, prevention and treatment. Leuk Lymphoma 41, 225-276 
Levine EG, Bloomfield CD (1992): Leukemias and myelodysplastic syndromes secondary to drug, radiation and environmental expoture. Semin Oncol $\underline{19}, 47-84$

Lörper M, Schulz WA, Morel F, Warskulat U, Sies H (1996): Positive and negative regulatory regions in promoters of human glutathione transferase alpha genes. Biol Chem Hoppe-Seyler $\underline{377}$, 39-46

Lörper M, Clairmont A, Carlberg C, Sies H (1998): Identification of two activating elements in proximal promoter region of the human glutathione transferase-A1 and -A2 genes. Arch Biochem Biophys $\underline{359}, 122-127$

Lu G, Yin CC, Medeiros LJ, Abruzzo LV (2009): Deletion 15q as the sole abnormality in akute myeloid leukemia: report of three cases and review of the literature. Cancer Genet Cytogenet $\underline{188}, 118-123$

Meyer DJ, Coles B, Pemble SE, Gilmore KS, Fraser GM, Ketterer B (1991): Theta, a new class of glutathione transferases purified from rat and man. Biochem $\mathrm{J} \underline{274}$, 409414

Morel F, Fardel O, Meyer DJ, Langouet S, Gilmore KS, Meunier B, Tu CPD, Kensler TW, Ketterer B Guillouzo A (1993): Preferential increase of glutathione Stransferase class $\alpha$ transcripts in cultured human hepatocytes by phenobarbital, 3methylcholanthrene and dithiolethiones. Cancer Res 53, 231-234

Morel F, Schulz WA, Sies H (1994): Gene structure and regulation of expression of human glutathione S-transferases alpha. Biol Chem Hoppe-Seyler $\underline{375}$, 641-649

Morel F, Rauch C, Coles B, Le Ferrec E, Guillouzo A (2002): The human glutathione transferase alpha locus: genomic organization of the gene cluster and functional characterization of the genetic polymorphism in the hGSTA1 promoter. Pharmacogenetics $\underline{12}, 277-286$ 
Nebert DW (1997): Polymorphisms in drug-metabolizing enzymes: What is their clinical relevance and why do they exist?. Am J Hum Genet $\underline{60}$, 265-271

Oniki K, Hori M, Takata K, Yokoyama T, Mihara S, Marubayashi T, Nakagawa K (2008): Association between glutathione S-transferase A1, M1 and T1 polymorphisms and hypertention. Pharmacogenet Genomics $\underline{18}$, 275-277

Pagano L, Pulsoni A, Tosti ME, Avvisati G, Mele L, Mele A, Martino B, Visani G, Cerri R, Di Bona E, Invernizzi R, Nosari A, Clavio M, Allione B, Coser P, Candoni A, Levis A, Camera A, Mellilo L, Leone G, Mandelli F (2001): Clinical and biological features of acute myeloid leukemia occurring as second malignancy: GIMEMA archive of adult acute leukemia. Br J Haematol 112, 109-117

Paumi CM, Ledford BG, Smitherman PK, Townsend AJ, Morrow CS (2001): Role of multidrug resistance protein 1 (MRP1) and glutathione S-transferase A1-1 in alkylating agent resistance. Kinetics of glutathione conjugate formation and efflux govern diffential cellular sensitivity to chlorambucil versus melphalan toxicity. J Biol Chem 276, 7952-7956

Pedersen-Bjergaard J (1995): Long-term complications of cancer chemotherapy. J Clin Oncol $\underline{13}, 1534-1536$

Pedersen-Bjergaard J, Rowley JD (1994): The balanced and the unbalanced chromosome aberrations of acute myeloid leukemia may develop in different ways and may contribute differently to malignant transformation. Blood $\underline{83}, 2780-2786$

Pedersen-Bjergaard J, Specht L, Larsen SO, Ersboll J, Struck J, Hansen MM, Hansen HH, Nissen NI (1987): Risk of therapy-related leukemia and preleukemia after hodgkin`s disease. Relation to age, cumulative dose of alkylating agents, and time from chemotherapy. Lancet $\underline{1987,2}, 83-88$ 
Pemple SE, Schroeder KR, Spencer SR, Meyer DJ, Hallier E, Bolt HM, Ketterer B, Taylor JB (1994): Human glutathione S-transferase Theta (GSTT1): cDNA cloning and the caracterization of a genetic polymorphism. Biochem $\mathrm{J} \underline{300}, 271-276$

Pemple SE, Wardle AF, Tayler JB (1996): Glutathione-S-transferase class Kappa: characterization by the cloning of rat mitochondrial GST and identification of a human homologue. Biochem J $\underline{319}$, 749-754

Ritter CA, Sperker B, Grube M, Dressel D, Kunert-Keil C, Kroemer HK (2002): Overexpression of glutathione S-transferase A1-1 in ECV 304 cells protects against busulfan mediated G2-arrest and induces tissue factor expression. Br J Pharmacol $\underline{137}, 1100-1106$

Roman-Unfer S, Bitran JD, Hanauer S, Johnson L, Rita D, Booth C, Chen K (1995): Acute myeloid leukemia and myelodisplasia following intensive chemotherapy for breast cancer. Bone Marrow Transplant 16, 163-168

Schröder KR, Hallier E, Peter H, Bolt HM (1992): Dissociation of a new glutathione S-transferase activity in human erythrocytes. Biochem Pharmacol $\underline{43}$, 1671-1674

Schulz TG, Hallier E (1999): Die Bedeutung von genetischen Polymorphismen Fremdstoff metabolisierender Enzyme in der Arbeitsmedizin. Arbeitsmed Sozialmed Umweltmed 34, 307-314

Schulz TG, Degen G, Foth H, Kahl R, Kramer PJ, Lilienblum W, Schrenk D, Schweinfurth H (2002): Stellungnahme zur Bedeutung von genetischen Polymorphismen von Fremdstoff metabolisierenden Enzymen in der Toxikologie. Umweltmed Forsch Prax $\underline{7}, 232-246$

Seidegard J, Vorachek WR, Pero RW, Pearson WR (1988): Hereditary differences in the expression of human glutathione transferase active on trans-stilbene oxide are

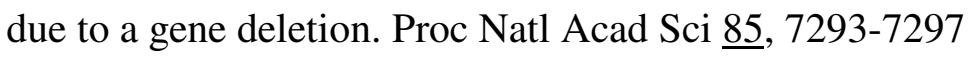


Seidegard J, Pero RW, Markowitz MM, Roush G, Miller DG, Beattie EJ (1990): Isoenzyme(s) of glutathione transferase (class $\mu$ ) as a marker for the susceptibility to lung cancer: a follow up study. Carcinogen $\underline{11}$, 33-36

Smitherman PK, Townsend AJ, Kute TE, Morrow CS (2004): Role of multidrug resistance protein $2(\mathrm{MRP} 2, \mathrm{ABCC} 2)$ in alkylating agent detoxification: MRP2 potentiates glutathione S-transferase A1-1-mediated resistance to chlorambucil cytotoxicity. J Pharmacol Exp Ther $\underline{308}$, 260-267

Stanulla M, Schrappe M, Brechlin AM, Zimmermann M, Welte K (2000): Polymorphisms within glutathione S-transferase genes (GSTM1, GSTT1, GSTP1) and risk of relapse in childhood B-cell precursor acute lymphoblastic leukemia: a case-control study. Blood 95, 1222-1228

Stoehlmacher J, Park DJ, Zhang W, Groshen S, Tsao-Wei DD, Yu MC, Lenz HJ (2002): Association between glutathione S-transferase P1, T1 and M1 genetic polymorphism and survival of patients with metastatic colorectal cancer. J Natl Cancer Inst 94, 936-942

Sweeney C, McClure GY, Fares MY, Stone A, Coles BF, Thompson PA, Korourian S, Hutchins LF, Kadlubar FF, Ambrosone CB (2000): Association between survival after treatment for breast cancer and glutathione S-transferase P1 Ile ${ }^{105}$ Val polymorphism. Cancer Res $\underline{60}, 5621-5624$

Sweeney C, Coles BF, Nowell S, Lang NP, Kadlubar FF (2002): Novel markers of susceptibility to carcinogens in diet: associations with colorectal cancer. Toxicology $\underline{181-182}, 83-87$

Sweeney C, Ambrosone CB, Joseph L, Stone A, Hutchins LF, Kadlubar FF, Coles BF (2003): Association between a glutathione S-transferase A1 promoter polymorphism and survival after breast cancer treatment. Int J Cancer $\underline{103}$, 810-814 
Tallman MS, Gray R, Bennett JM, Variakojis D, Robert N, Wood WC, Rowe JM, Wiernik PH (1995): Leukemogenic potential of adjuvant chemotherapy for earlystage breast cancer: the eastern cooperative oncology group experience. J Clin Oncol $\underline{13}, 1557-1563$

Tetlow N, Liu D, Board P (2001): Polymorphism of human alpha class glutathione transferases. Pharmacogenetics $\underline{11}, 609-617$

Travis LB, Li CY, Zhang ZN, Li DG, Yin SN, Chow WH, Li GL, Dosemeci M, Blot W, Fraumeni JF Jr. (1994): Hematopoietic malignancies and related disorders among benzene-exposed workers in China. Leuk Lymphoma 14, 91-102

Van Ommen B, Bogaards JJP, Peters WHM, Blaauboer B, Van Bladeren PJ (1990): Quantification of human hepatic glutathione S-transferases. Biochem J $\underline{269}$, 609-613

Wang L, Groves MJ, Hepburn MD, Bowen DT (2000): Glutathione S-transferase enzyme expression in hepatopoietic cell lines implies a differential protective role for $\mathrm{T} 1$ and A1 isoenzymes in erythroid and for M1 in lymphoid lineages. Haematologica $\underline{85}, 573-579$

Zhong S, Wyllie AH, Barnes D, Wolf CR, Spurr NK (1993): Relationship between the GSTM1 genetic polymorphism and susceptibility to bladder, breast and colon cancer. Carcinogen $\underline{14}, 1821-1824$

Zhong S, Huang M, Yang X, Liang L, Wang Y, Romkes M, Duan W, Chan E, Zhou SF (2006): Relationship of glutathione S-transferase genotypes with side-effects of pulsed cyclophosphamide therapy in patients with systemic lupus erythematosus. $\mathrm{Br}$ J Clin Pharmacol $\underline{62}, 457-472$ 


\section{Danksagung}

Allen, die mich bei meiner Dissertation unterstützt und mir die Durchführung überhaupt erst möglich gemacht haben, insbesondere

Herrn Prof. Dr. med. Ernst Hallier, dem Leiter der Abteilung Arbeits- und Sozialmedizin, für die Gelegenheit zur Arbeit an diesem Thema und die guten Arbeitsbedingungen in seiner Abteilung,

Herrn Priv. Doz. Dr. rer. nat. Thomas Schulz für die Betreuung und Hilfe bei den Problemen der experimentellen Durchführung und des theoretischen Hintergrundes,

Gesa Homan und Pia Ballhausen für die tägliche Zusammenarbeit im Labor und insbesondere die unverzichtbare Hilfe bei vielen Versuchen,

möchte ich hiermit danken. 